\title{
20. LOG-BASED POROSITY OF ODP SITES ON THE CASCADIA ACCRETIONARY PRISM ${ }^{1}$
}

\author{
Richard D. Jarrard, ${ }^{2}$ Mary E. MacKay, ${ }^{3}$ Graham K. Westbrook, ${ }^{4}$ and Elizabeth J. Screaton ${ }^{5}$
}

\begin{abstract}
Fluid flow is a key to the dynamics of accretionary prisms, and porosity at drill holes can provide valuable clues to that flow in two ways: (1) lateral changes in porosity/depth trends provide estimates of fluid expulsion volumes; and (2) porosity/velocity relationships can be used to determine two-dimensional porosity structure from seismic velocities. We have determined logbased porosities for four holes on the Cascadia accretionary prism, as well as for nearby reference Site 888 .

Before interpretation of the geophysical logs, substantial reprocessing was needed, particularly for borehole corrections. We used borehole-corrected gamma-ray logs to determine lithology variations (sand vs. silty clay) at each site; at Site 888 the caliper $\log$ was also a useful lithology log. Sonic logs were reprocessed to remove noise. A recent algorithm for combining the high accuracy of deep resistivity logs with the high vertical resolution of shallow focused resistivity logs was successfully employed. We then used estimates of thermal gradient and salinity to determine formation factor from resistivity. One-third to two-thirds of the density logs had to be rejected because of poor pad contact. The remaining portions, after conversion to porosity based on index-property measurements of grain density, allowed us to determine the coefficients needed for conversion of formation factor logs to porosity.

These resistivity-based logs, which we consider to be our best estimates of porosity variation as a function of depth, agree in general with density and neutron logs, but they are more continuous and higher in signal-to-noise ratio. Core porosities are similar to the porosity logs, but offset slightly owing to rebound or missed fracture porosity. The porosity logs exhibit dramatic intersite variations in both average porosity and consistency with empirical trends. The sites exhibit no systematic lateral changes in porosity; total porosity (both intergranular and fracture porosity) of the studied prism sediments is comparable to porosities of the unconsolidated reference sediments.

Of the published relationships between velocity and porosity, only that of Hyndman, Moore, et al. (1993) fits data from our reference sections reasonably well. Only at reference Site 888 did we identify an influence of lithology on porosity/formationfactor and porosity/velocity relationships. Within the prism, cementation accompanied by fracturing dominates lithology influences on both pore and intergranular-contact geometry. As a result, formation factors and velocities are substantially higher than in unconsolidated reference sediments of the same porosity. For the conversion of seismic velocities within accretionary prisms to porosities, the velocity/porosity relationship based on Leg 146 prism sediments is more appropriate than those from undeformed sediments. We caution, however, that observed variability in cementation, and secondarily in compressioninduced compaction and fracturing, creates substantial uncertainty in the local velocity/porosity transform for prism sediments.
\end{abstract}

\section{INTRODUCTION}

Ocean Drilling Program (ODP) Leg 146 examined the complex interplay of fluid flux and structural evolution that occurs at accretionary prisms. The prime objective of Leg 146 was to determine fluid fluxes in the Vancouver and Oregon accretionary prisms, because fluid flow is the key to the dynamics of accretionary prisms (e.g., Davis et al., 1983; Moore and Vrolijk, 1992). A variety of experiments examined fluid flow on scales ranging from years to millions of years and from meters to tens of kilometers. Aspects of diffuse outflow of fluids from an accretionary wedge were investigated at the Vancouver margin, whereas the drill sites off Oregon examined focused flow through thrust faults. The drilling strategy con isted of a reference hole seaward of Vancouver prism (Site 888), one location on the Vancouver accretionary prism (Sites 889 and 890), and two locations on the Oregon accretionary prism (Sites 891 and 892). A sec-

'Carson, B., Westbrook, G.K., Musgrave, R.J., and Suess, E. (Eds.), 1995. Proc. ODP. Sci. Results, 146 (Pt. 1): College Station, TX (Ocean Drilling Program).

${ }^{2}$ Department of Geology and Geophysics, University of Utah, Salt Lake City, UT 84112, U.S.A.

${ }^{3}$ Department of Geology and Geophysics, University of Hawaii, Honolulu, HI 96822, U.S.A.

${ }^{4}$ School of Earth Sciences, University of Birmingham, Birmingham B15 2TT, U.K.

${ }^{5}$ Department of Earth and Environmental Sciences, Lehigh University, Bethlehem, PA 18015, U.S.A. ondary objective of Leg 146 was to test models for the origin of bottom-simulating reflectors (BSRs) and their relationship to methane hydrates. Downhole measurements were crucial for attaining both fluid-flow and BSR objectives. Many types of downhole measurements were employed on Leg 146 (e.g., ADARA and WSTP temperatures, drillstring packer, CORK, LAST II, and an oblique seismic experiment); this report focuses only on Schlumberger logging measurements obtained by the geophysical tool string (spectral gamma ray, sonic velocity, density, resistivity, and neutron-porosity logs).

In this paper, we seek to provide a strong foundation for other studies of the large-scale, long-term fluid budget of Cascadia accretionary prism. We use logs from the five logged holes to calculate continuous records of porosity as a function of depth. Between-site variation in the porosity/depth relationship provides an estimate of the amount of fluid expulsion (Bray and Karig, 1985). Thus, these porosity logs can contribute to the continuing refinement of inferred dewatering patterns for the Cascadia prisms (Davis et al., 1990; Carson et al., 1991; Le Pichon et al., 1991).

A few profiles of porosity vs. depth provide a tantalizing, but inadequate, overview of the fluid expulsion pattern of an accretionary prism. A far more powerful documentation of the two-dimensional porosity structure of a prism can be determined from multichannel seismic (MCS) stacking velocities (e.g., Bangs et al., 1990; Carson et al., 1991; Hyndman, Wang et al., 1993; Cochrane, Moore et al., 1994; 
Yuan et al., 1994) or from prestack-migration velocities (MacKay et al., 1992). Both are obtainable from the excellent seismic lines across the Vancouver and Oregon prisms.

The fundamental limitation to determining two-dimensional porosity structure from seismic velocities is doubt about the conversion from velocity to porosity. The relationship between velocity and porosity is well known for normally compacted low-porosity sediments (Wyllie et al., 1956). For high-porosity sediments, however, attempts to determine the porosity/velocity relationship (Raymer et al., 1980; Nobes, 1989) have lacked universality. For terrigenous sediments, application of a general empirical relationship (e.g., Hamilton, 1976, 1979) or of a relationship determined for a different accretionary prism (e.g., Hyndman, Moore, et al., 1993) will probably lead to significant unquantified errors. Local empirical relationships, preferably including the influence of fracturing, need to be determined for Cascadia prisms.

Westbrook, Carson, Musgrave, et al. (1994) undertook shipboard analyses of porosity/depth and velocity/porosity relationships for some Leg 146 logs, but these reconnaissance studies lumped varied lithologies and were undertaken before borehole correction of the logs. For example, shipboard plots of velocity vs. porosity for Sites 888 and 889 ignored lithologic variations and simply used density or neutron porosity, in spite of substantial differences in porosities inferred from different log types; resulting crossplots of velocity vs. estimated porosity exhibit a very high dispersion.

In most of our analyses, unlike similar analyses undertaken by the oil industry, we can assume that all pores are filled with seawater. Possible important exceptions are zones containing gas hydrates (clathrates) and free gas. Log responses can be used to detect occurrences of gas hydrates (e.g., Mathews and von Huene, 1985). For example, velocities that are a few percent higher than predicted from resistivity and neutron porosity suggest the presence of a few meters of gas hydrates overlying the BSR at Hole 889B. Hyndman and Spence (1992) proposed a model for the origin of gas hydrates and associated BSRs, in which the presence of high-velocity gas hydrates alone creates a sudden uphole velocity increase at the BSR. Shipboard log analyses, however, suggest that gas hydrates are volumetrically minor (Westbrook, Carson, Musgrave, et al., 1994), so we do not include their possible influence in the present analyses. Free gas is present beneath the BSRs at Sites 889 and 892 (MacKay et al., this volume), but its effect on most log responses is minimal because of the combination of low concentrations and invasion of the formation by drill fluids (Westbrook, Carson, Musgrave, et al., 1994). The only logs that exhibit a substantial free-gas effect are the sonic logs beneath the BSRs at Sites 889B and 892; we exclude those segments of $\log$ from these analyses.

ASCII files of almost all of the "raw" logs used in this study are available on CD-ROM in the Initial Reports volume (Westbrook, Carson, Musgrave, et al., 1994). ASCII files of the remaining raw logs (sonic and merged logs) and of the processed logs shown in our figures are available via e-mail; send requests to rich@westlog. utah.edu.

\section{GEOLOGIC SETTING}

ODP Site 888 was drilled in the northern Cascadia Basin, penetrating the northern portion of Nitinat Fan at a location $7 \mathrm{~km}$ seaward of the toe of Vancouver accretionary prism. This site was intended as a reference site, to provide porosities and pore-water geochemistries of sediments prior to incorporation into the accretionary prism. Time limitations precluded drilling an analogous reference site for Oregon accretionary prism. Site 174 (Shipboard Scientific Party, 1973) was drilled on the Astoria Fan at a suitable reference location during early Deep Sea Drilling Project (DSDP), but it was spot cored and not logged. Thus, Site 888 serves not only as a direct reference site for the Vancouver accretionary prism, but also as an indirect reference site for Oregon accretionary prism.
Site 888 penetrated the top $600 \mathrm{~m}$ of the 2500 -m-thick sequence of terrigenous turbidites. This upper portion of the section consists of sands and clayey silts, deposited by turbidites in middle and outer submarine-fan environments. Sedimentation rates were very highabout $1 \mathrm{~m} / 1000 \mathrm{yr}$ - possibly resulting in undercompaction. One logging run of the geophysical tool string was undertaken at Hole $888 \mathrm{C}$. Substantial hole caving filled the hole bottom and limited logging to the top $509 \mathrm{~m}$. Pipe was set at $91 \mathrm{~m}$ below seafloor (mbsf), so openhole logging was from 91 to 509 mbsf.

Sites 889 and 890 were drilled on the middle continental slope offshore of Vancouver Island, $18 \mathrm{~km}$ landward of the toe of Vancouver accretionary prism. Penetration at Site 889 was to $386 \mathrm{mbsf}$, and penetration at 4-km distant Site 890 was to $48 \mathrm{mbsf}$. The top 123-128 m consists of clayey silts and silty clays with very thin $(<8 \mathrm{~cm})$ sand layers, deposited during the Quaternary as hemipelagites and turbidites in a slope environment; the lower $20 \mathrm{~m}$ of this interval is a slump. The section below $123-128 \mathrm{mbsf}$ is lithologically similar but is structurally quite different: it consists of upper Pliocene to lower Pleistocene abyssal-plain clayey silts and silty clays that have been consolidated and heavily fractured by accretionary prism deformation. The BSR is at $224 \mathrm{mbsf}$ in Hole $889 \mathrm{~B}$ and is caused by free gas below the BSR (MacKay et al., this volume).

Holes $889 \mathrm{~A}$ and $889 \mathrm{~B}$ were logged with the geophysical string and Formation MicroScanner (FMS). A vertical seismic profile (VSP) was run at Hole 889B and a CORK was emplaced in Hole $889 \mathrm{C}$; results of these downhole experiments are reported by MacKay et al. (this volume) and Carson and Westbrook (this volume). Hole caving at Holes 889A and 889B was extreme, resulting in hole fill, pipe sticking, and bridging. Openhole logs were obtained at Hole 889A for the interval $68.4-256.6 \mathrm{mbsf}$, and at Hole 889B for 60.4 255.7 mbsf.

Site 891 was drilled at the toe of the Oregon accretionary prism, less than $1 \mathrm{~km}$ landward of the outcrop of the frontal thrust at the seafloor. The cored sediments consist of upper Quaternary clayey silts and sands, deposited as proximal fan sediments on the Astoria Fan and subsequently uplifted and folded by the seaward-advancing accretionary prism. Deformation and consolidation increase downhole from the seafloor to the frontal thrust, which was identified at about $375 \mathrm{mbsf}$ in cores, or at about $369 \mathrm{mbsf}$ on the basis of log responses. Fractures are abundant between 198 and 375 mbsf. Sediments below the thrust, in contrast, appear to be less fractured and less consolidated than those immediately above.

Hole $891 \mathrm{C}$ was drilled as a dedicated hole for downhole logging and for an oblique seismic experiment. Penetration was $492 \mathrm{~m}$, but hole conditions were even worse than at Site 889: logging operations included fill, bridging, stuck pipe, use of the sidewall entry sub, and separate logging of two depth intervals. In the top depth interval, only the geophysical tool string was run openhole, whereas the lower depth interval was logged with the geophysical, FMS, and geochemical strings and both a VSP and oblique seismic experiment were run there. Openhole geophysical logs were obtained over the interval $101.2-423.7 \mathrm{mbsf}$, with a $15-35-\mathrm{m}$ gap between the two runs at about $300 \mathrm{mbsf}$

Site 892 was drilled on the Oregon continental slope, $17 \mathrm{~km}$ landward of the toe of the accretionary prism. Largely incoherent seismic reflections and surface offsets of faults suggest that both distributed and localized deformation are active. Different holes at this site penetrated an active out-of-sequence thrust at 50-75 mbsf. Penetrated sediments are Pliocene silty clays, clayey silts, and some sands. The sediments are richer in biogenic material than those at the other sites, and their depositional environment is characterized by alternating hemipelagic and distal turbidite facies. Fracture abundance increases downhole. Based on a VSP, the BSR in Hole $892 \mathrm{C}$ is at $74 \mathrm{mbsf}$ and is attributable to presence of free gas below that depth (MacKay et al., this volume).

A packer test (Screaton et al., this volume) and CORK emplacement were undertaken at Hole 892B. At Hole 892C, which penetrated to $176 \mathrm{mbsf}$, downhole measurements consisted of the geophysical 
and FMS logging strings and a VSP. Because of very shallow (176 $\mathrm{mbsf}$ ) penetration of the hole and the likelihood of fill, the usual geophysical string was broken into two shorter, separate strings. Openhole geophysical logs were obtained for the interval 32.6-136.3 mbsf.

\section{LOG REPROCESSING AND QUALITY CONTROL}

Original ODP logs may have depth shifts with respect to coring depths, due to a combination of cable stretch and pipe-depth uncertainties. Logs reported here have been depth shifted by up to $2 \mathrm{~m}$ by the Borehole Research Group (BRG), based on identifying either the base of the bottomhole assembly or the seafloor on the logs. These shifts are described by the Shipboard Scientific Party (1994a) and in the backpocket CD-ROM in Westbrook, Carson, Musgrave, et al. (1994). These depths differ slightly from those in the shipboard logging reports of Westbrook, Carson, Musgrave, et al. (1994). This study includes some shipboard logs (primarily our reprocessed sonic logs) rather than those provided in the CD-ROM, and we have used the gamma-ray log to depth shift these shipboard logs to the BRGestablished standard.

Often the same interval is logged more than once by each tool. For example, geophysical logging normally includes a downgoing log for most tools, a main upgoing run, and a short upgoing repeat section for quality control. Normally we present data here only from the main upgoing run, but in some cases we have merged logs from different runs: where downgoing or repeat runs extend slightly deeper or shallower than the main run, and where spurious-data intervals (generally dramatic spikes) occur on the main run.

\section{Borehole Conditions}

Variations in hole size degraded the extent and initial quality of most logs from Leg 146. Hole size at the five logged sites was highly variable, as shown by caliper logs obtained by both the lithodensity and FMS tools. Unconsolidated sands and pervasively fractured intervals are prone to collapse and caving into the borehole, creating intervals of large hole diameter and generating hole fill that prevented logging of the lowest $40-140 \mathrm{~m}$. These problems were so severe at Hole 889A that they affected our choice of logging tools at Hole 889B: we omitted density logging because of expected poor density$\log$ quality and to permit us to reach deeper in the fill-prone hole with other tools. Hole problems dictated logging of Site 891 in two stages, with a $15-35-\mathrm{m}$ gap between logged intervals.

The different tools of the geophysical tool string vary dramatically in their sensitivities to hole size and to variability in hole size, as well as in the accuracy of post-cruise correction for these variables. Gamma-ray logs read too low in enlarged-hole intervals, but reasonably accurate correction is possible. Neutron logs read too high and shallow resistivity logs read too low in a large-diameter hole; correction of both is accurate only if one knows both the hole diameter and position of the tool within the hole (standoff). We measure hole size, but standoff is certainly highly variable and not accurately estimable. Deep resistivity and sonic logs are relatively insensitive to hole size, although ragged hole can degrade sonic quality. Density and FMS logging require pad contact, so data are unreliable when hole size exceeds the dynamic range of the pad eccentralizer $(43 \mathrm{~cm}$ for density and $38 \mathrm{~cm}$ for the FMS); rapid hole-size variations also degrade pad contact.

The gamma-ray logs used here have been borehole corrected and alpha filtered post-cruise by BRG (Shipboard Scientific Party, 1994a). Compared to the uncorrected logs used in shipboard interpretations, the corrected logs are smoother and are higher by 5-15 API units, with the greatest increases applied to the largest-diameter intervals because water attenuates natural gamma rays generated by the formation. Overall gamma-ray character seldom is changed markedly.

Sonic logs used here were reprocessed on-board ship to remove spurious data, using an algorithm that we developed on ODP Leg 105 (Shipboard Scientific Party, 1987). Density and resistivity logs used here have been substantially edited and reprocessed, respectively, as described in the next two sections.

\section{Density Editing}

Density tools determine formation bulk density by measuring the absorption of gamma rays emitted by a radioactive source. The Schlumberger high-temperature lithodensity tool (HLDT) used in ODP since Leg 125 uses a pad containing a radioactive source and two detectors, which are pressed against the borehole wall by a spring arm; the separation of the spring arm from the tool string indicates hole diameter. When rough borehole allows borehole fluid between parts of the pad and the borehole wall, or when borehole diameter is larger than the 43-cm maximum opening of the spring arm, bulk-density measurements are erroneously low; they are intermediate between formation and fluid densities. This condition was extremely common in the Leg 146 density logs.

The two detectors provide a consistency test that attempts to compensate for minor departures from firm pad contact. The $\Delta \rho \log$ indicates the size of this correction, and large values of $\Delta p$ are a warning that the bulk density estimate may be unreliable. The HLDT also determines photoelectric factor, a measure of the photoelectric absorption of low-energy gamma rays. Photoelectric factor is dependent primarily on matrix lithology and is normally considered to be relatively independent of porosity, but this generalization is better for the low porosities commonly found in the petroleum industry than for the high porosities of Leg 146. Loss of pad contact causes anomalously low values of the photoelectric factor as well as low density measurements.

We used a combination of caliper, photoelectric factor, and $\Delta p$. logs to guide deletion of erroneous patches of the density logs of Leg 146 (Figs. 1A and 1B). This editing is subjective; no objective alternative is available. In marginal cases of uncertain reliability, we deleted the data. Our shipboard editing (Westbrook, Carson, Musgrave, et al., 1994) did not use the photoelectric factor log, and it deleted much less data than the present study. The percentage of rejected data ranged widely: $33 \%, 63 \%, 46 \%$, and $33 \%$ at Holes $888 \mathrm{C}, 889 \mathrm{~A}$, $891 \mathrm{C}$, and $892 \mathrm{C}$, respectively. We think that nearly all of the retained data are accurate measurements of formation bulk density, but some erroneously low values probably remain.

The Leg 146 density logs have many more unreliable patches than do the other log types. As we will show in a subsequent section, however, the subset of reliable density measurements (Fig. 1B) is quite useful as a calibration of other porosity-sensitive logs - in particular the resistivity $\log$.

\section{Resistivity Reprocessing}

ODP runs three resistivity logs, with different vertical resolutions and depths of penetration into the formation. In general, resistivity logs have the highest signal-to-noise ratio and best replicability of any $\log$ run in ODP.

In enlarged holes, resistivity measurements measure a combination of borehole-fluid resistivity and the much higher formation resistivity, yielding a composite measurement that underestimates formation resistivity. The impact is large for the spherically focused $\log$ (SFL), which generates electrical currents with a short depth of penetration $(0.6 \mathrm{~m})$. The effect is much smaller for the deep induction $\log$ (ILD), which "sees" about $1.3 \mathrm{~m}$ into the formation. Resistivity logs can be borehole corrected, if hole size and standoff are known. Standoff in ODP holes, however, is too variable to estimate even ap- 

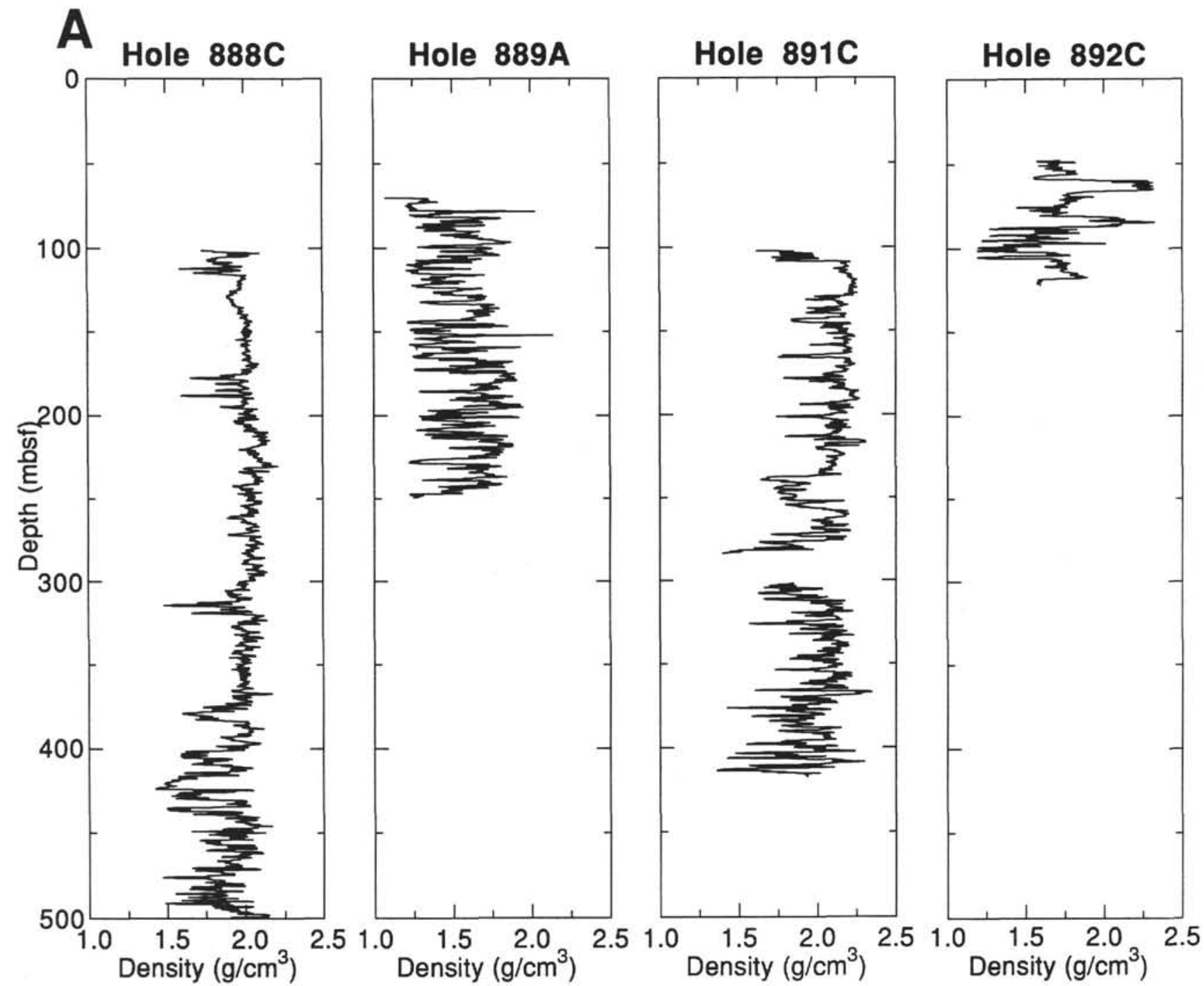

Figure 1. Density logs obtained during Leg 146, before (A) and after (B) deletion of data that are unreliable because of loss of pad contact with the borehole wall.

proximately. For a postulated standoff of $6 \mathrm{~cm}$ and hole size of $50 \mathrm{~cm}$, a typical fluid resistivity of $0.2 \mathrm{ohm}$-meters, and a typical formation resistivity of $2 \mathrm{ohm}$-meters, the borehole correction for the ILD is only $2 \%$, whereas it is $28 \%$ for the medium induction log and much larger for the SFL. Therefore, we use the ILD as the best indicator of formation resistivities. We shall neglect borehole correction of the ILD because it is not feasible to make the corrections accurately and because $2 \%$ (or even $5 \%$ ) error is minor in a log that varies by more than an order of magnitude.

The disadvantage of using the ILD is its vertical resolution of 1.5 $\mathrm{m}$, a factor of two to four wider than that of most other logs. Unless the vertical resolutions of the other logs are degraded by smoothing to a similar resolution, crossplots of ILD vs. other logs can exhibit an increase in dispersion due to this resolution mismatch. The SFL, with a vertical resolution of about $76 \mathrm{~cm}$, is the only resistivity $\log$ that has a resolution similar to the other geophysical logs. Yet the SFL reads too low by a variable amount, because its response is very sensitive to changes in hole size. Ideally, we would use an SFL that is reliably borehole corrected by calibration to the ILD.

Peter Jackson has developed an algorithm that uses the ILD to calibrate the SFL, thereby obtaining a log with the accuracy of the ILD and the high resolution of the SFL (Jackson and Jarrard, 1993). The method begins by using the ILD response function (Hardman and Shen, 1986) - the ILD log response to a step change in formation properties. Application of this response function to the SFL generates a predicted ILD log. The difference between observed and predicted ILD is then used as a correction to be added to the original SFL. The ILD response function is applied to this corrected SFL (SFLC) and the predicted ILD is again compared to the ILD. Further corrective iterations can be applied; Jackson and Jarrard (1993) used two SFLC iterations, but here we use only one because ILD residuals are quite small after only one correction. This algorithm worked well for the carbonate sediments of ODP Leg 133, a leg in which large-diameter hole was very common and lithology was fairly uniform. The technique has not previously been used at sites with dominantly terrigenous sediments or with as much high-frequency hole-size variation as those on Leg 146.

Figure 2 illustrates the application of dynamic SFL calibration to some representative intervals of Leg 146 logs. Often we see that the raw SFL records lower resistivities than the ILD, particularly in the lowest-resistivity, washed-out intervals of borehole. The dynamically calibrated SFL (SFLC) always maintains the character of the orig- 

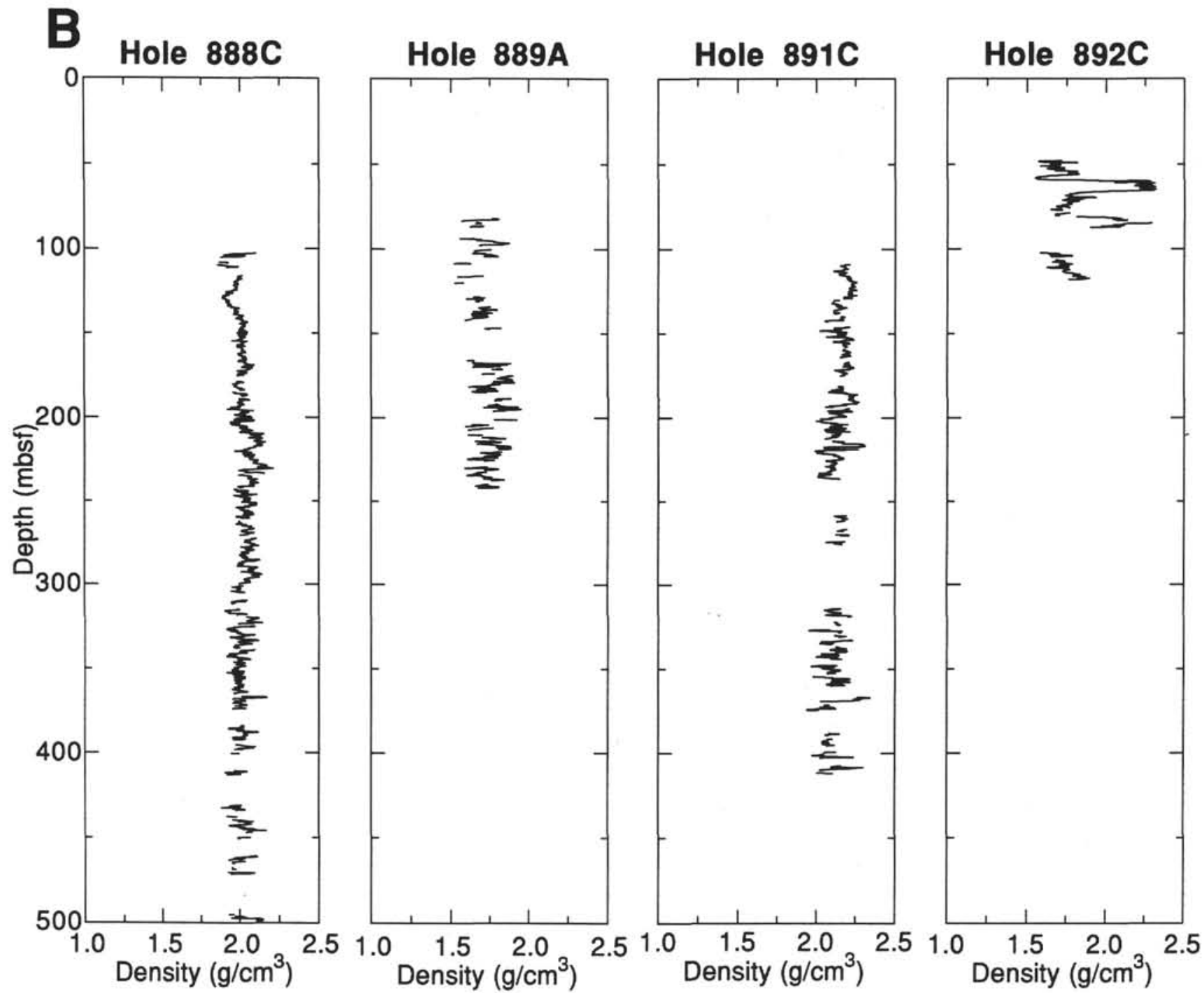

Figure 1 (continued).

inal SFL, but it can decrease the amplitude variations between adjacent very low-and high-resistivity zones. The average resistivity of the SFLC of course agrees with the ILD. The predicted ILD, based on applying ILD tool response to the SFLC, nearly always agrees very closely with the observed ILD.

We tentatively conclude from the pervasiveness of behavior such as in Figure 2 that the dynamic SFL calibration has succeeded remarkably well in its objective of combining SFL resolution with ILD accuracy. In an attempt to test this conclusion by crossplotting segments of SFL, SFLC, and ILD against a sonic log, however, we found that correlation coefficients for SFLC vs. sonic were comparable to, not superior to, those for SFL vs. sonic and ILD vs. sonic.

Dynamic SFL calibration is not a magic bullet for removal of all borehole effects. The intervals that are most prone to washout are those at which pipe is held stationary for a prolonged period while fluid is "circulated" (i.e., pumped down the pipe and ideally up around the outside of the pipe to prevent sediment accumulation around the pipe and associated pipe sticking). This is exactly the situation during logging, particularly logging of Leg 146 sites because of the extreme problem of hole collapse. The last step in our openhole logging was normally to raise the pipe $9.4 \mathrm{~m}$ to obtain as much openhole $\log$ as possible. At Hole $889 \mathrm{~B}$, the deep resistivity log exhibits a rapid decrease in measured resistivity within the last $10 \mathrm{~m}$ of open- hole $\log$ before entering pipe (see figures in Westbrook, Carson, Musgrave, et al., 1994). We conclude that hole size there is so large that even the ILD is giving unreliably low values; that interval is deleted from the analyses and figures of this study.

\section{Formation Factor}

Measured formation resistivity $\left(\mathrm{R}_{0}\right)$ depends on two variables, formation factor (FF) and fluid resistivity $\left(\mathrm{R}_{\mathrm{w}}\right)$, according to the relationship $F F=R_{d} / R_{w}$. Formation factor, not formation resistivity, is the variable that is of most interest in this study, because it is a measure of intrinsic rock properties such as porosity and pore geometry. Therefore, we have converted observed resistivities to formation factors by estimating fluid resistivity variations. For interpretation of seafloor electromagnetic soundings, in contrast, the ILD logs shown in Westbrook, Carson, Musgrave, et al. (1994) are more appropriate.

To the first order, fluid resistivity depends on fluid temperature and salinity, and we have used estimates of these two variables to determine fluid resistivity variations based on Schlumberger (1991) chart Gen-9.

To the second order, fluid resistivity is also affected by ions other than sodium and chlorine (e.g., Schlumberger chart Gen-8), but we have not modeled variations in other ions. For salinities and temper- 


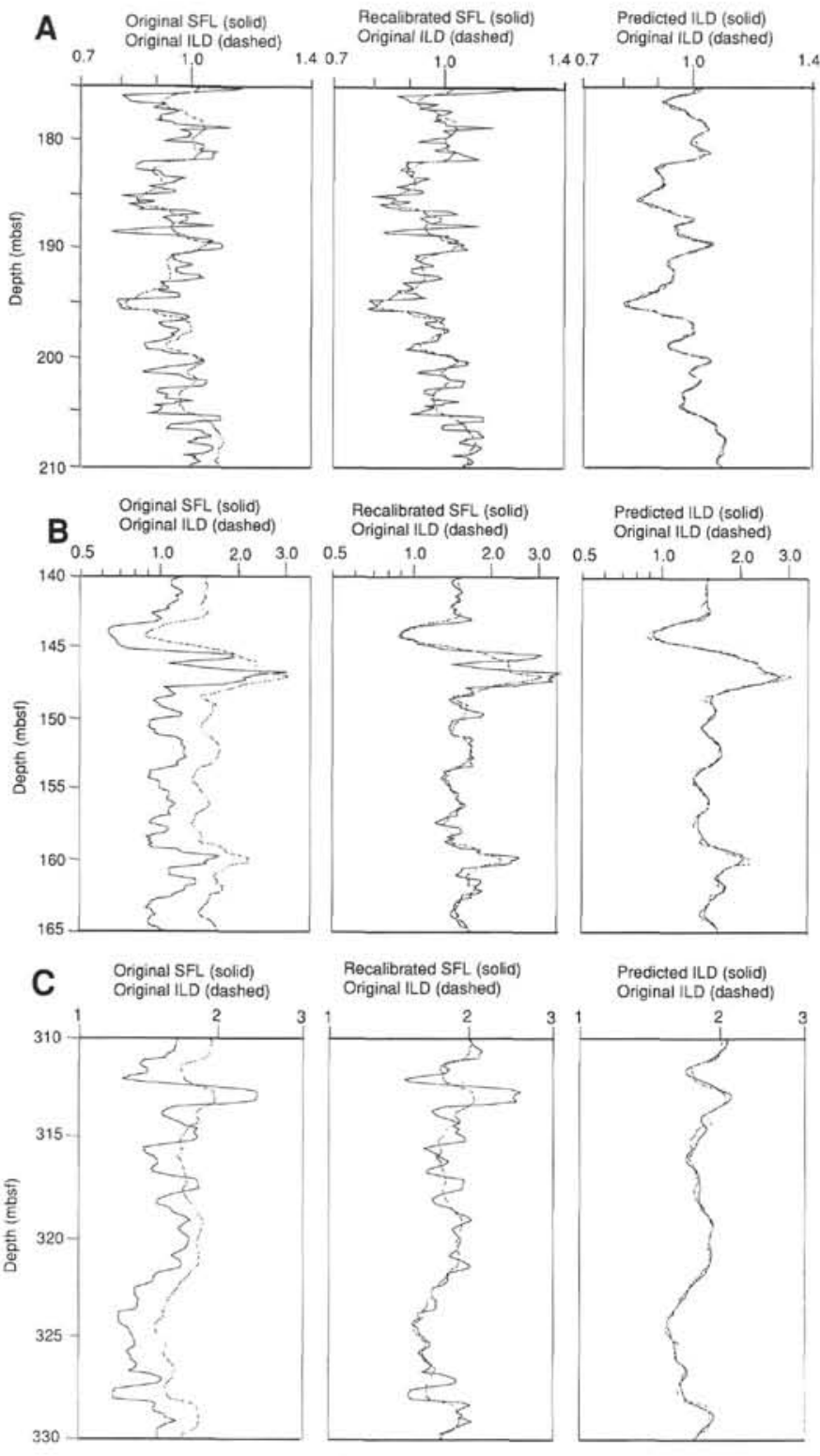

Figure 2. Three examples of the effect of using the deep induction $\log$ (ILD) to calibrate the shallow focused resistivity $\log$ (SFL). Resistivities are plotted on a logarithmic scale. Note that discrepancies between raw logs (left column) are removed by the reprocessing (central column), resulting in an excellent match of observed ILD to that predicted from the recalibrated SFL (right column). A. Hole 888C. B. Hole 889A. C. Hole 891C.

atures observed on Leg 146, a salinity error of \pm 1 ppt or a temperature error of $\pm 2{ }^{\circ} \mathrm{C}$ leads to an error in fluid resistivity of about $2 \%-4 \%$.

Our estimation of downhole variations of formation-fluid salinity is based on shipboard measurements of core interstitial waters (Westbrook, Carson, Musgrave, et al., 1994). For Site 888, we assumed a salinity of $36 \mathrm{ppt}$ at the seafloor, decreasing linearly to $32.1 \mathrm{ppt}$ at 250 mbsf, and constant at 32.1 ppt below 250 mbsf. For Site 889, we assumed a salinity of $32 \mathrm{ppt}$ at the seafloor, a linear decrease to $23 \mathrm{ppt}$ at $150 \mathrm{mbsf}$, a slight step decrease to $22.8 \mathrm{ppt}$ at $150 \mathrm{mbsf}$, and a linear decrease to $21.7 \mathrm{ppt}$ at $400 \mathrm{mbsf}$. For Site 891 , we assumed a constant salinity of $34.5 \mathrm{ppt}$ from the seafloor to $191 \mathrm{mbsf}$, then an abrupt drop to $33.5 \mathrm{ppt}$ at $191 \mathrm{mbsf}$, and a linear decrease to $32.5 \mathrm{ppt}$ at 500 mbsf. For Site 892, we assumed a salinity of $33 \mathrm{ppt}$ at the seafloor, a linear decrease to $30 \mathrm{ppt}$ at $68 \mathrm{mbsf}$, a slight drop to $29.5 \mathrm{ppt}$ at 68 mbsf, and then a linear decrease to $27.5 \mathrm{ppt}$ at $175 \mathrm{mbsf}$.

Measurement of the thermal gradient was a high priority of Leg 146 , and reliable estimates of the equilibrium thermal gradient were obtained at all sites except for Site 891 (Westbrook, Carson, Musgrave, et al., 1994). Borehole temperatures were logged at the same time as other logging at all sites, but because of major circulation of cool seawater both before and during logging, these borehole temperatures provide only a minimum estimate for equilibrium formation temperatures. Our measured thermal gradient within the borehole was typically $50 \%-80 \%$ of the equilibrium gradient (Westbrook, Carson, Musgrave, et al., 1994). For Site 891, in situ temperature measurements give only minimum estimates of $>17$ and $>25^{\circ} \mathrm{C} / \mathrm{km}$ for the thermal gradient, and temperature logging gives a minimum estimate of $>17^{\circ} \mathrm{C} / \mathrm{km}$ (Shipboard Scientific Party, 1994c). The few heat-flow measurements in the vicinity of this site are consistent with a pattern documented elsewhere on Cascadia Margin (Hyndman, Wang et al., 1993) of increasing heat flow as the toe of the prism is approached. We assumed an equilibrium thermal gradient of $60^{\circ} \mathrm{C} /$ $\mathrm{km}$ at this site, $20 \%$ higher than that at nearby Site 892 , but this estimate could be inaccurate by $\pm 10^{\circ} \mathrm{C} / \mathrm{km}$. Errors in thermal gradient affect the broad depth trend of the formation-factor log, not the shortwavelength fluctuations. The possible error in both fluid resistivity and formation factor is zero at the seafloor and increases downhole to $8 \%$, if the thermal gradient is $50^{\circ}$ or $70^{\circ} \mathrm{C} / \mathrm{km}$ rather than the $60^{\circ} \mathrm{C} /$ $\mathrm{km}$ that we assumed.

Drilling circulation decreases the temperatures not only of drillhole fluids but also of the borehole wall. With multiple temperature logging runs, it is possible to model the post-circulation temperature rebound of the formation and to predict the equilibrium thermal gradient (Carslaw and Jaeger, 1947). Such an extrapolation is not feasible, however, for the complex circulation histories of the Leg 146 sites. Estimation of fluid resistivity is therefore uncertain for the nearborehole environment examined by the SFL: the temperature is intermediate between borehole and equilibrium temperatures. The greater depth of penetration of the ILD, in contrast, is probably sufficient to see equilibrium temperatures. Therefore, we have used the equilibrium temperatures for our estimation of fluid resistivities. These assumed temperatures may be a few percent higher than actual temperatures.

For determining formation factors, the dynamically calibrated SFLC has an advantage in addition to those discussed in the previous section: it effectively adjusts the data to the deep fluid resistivity seen by the ILD. This fluid resistivity is easier to estimate reliably because equilibrium formation temperature is better known than the nearborehole temperature. Furthermore, the ILD is specifically designed to see far enough into the formation to measure the properties of formation fluids, not borehole fluids that sometimes invade a formation by $10-100 \mathrm{~cm}$ during drilling circulation. Thus, we can use salinities determined from interstitial water analyses with some confidence, rather than trying to estimate the invasion profile. Our use of these salinities, however, can be biased if gas hydrates were present in situ but have dissociated prior to water sampling; small percentages of gas hydrates are suspected above the BSRs at Sites 889 and 892 (Westbrook, Carson, Musgrave, et al., 1994).

\section{LITHOLOGY DETERMINATION}

The lithologies recovered in the Leg 146 cores are almost entirely sands, clayey silts, and silty clays. Within the intervals for which we have openhole logs, core recovery varied widely: $56 \%, 77 \%, 24 \%$, $13 \%$, and $52 \%$ for Site 888 , Hole 889 A, Hole 889 B, Site 891 , and Site 892 , respectively. Thus, the cores do not resolve the detailed distributions of lithologies as a function of depth. We also cannot estimate 
percentages of different lithologies precisely from core data, because of lithologically dependent core recovery. For example, sand recovery is often much less than recovery of clayey silt and silty clay.

The gamma-ray log is frequently used as a sand/shale log, both by the petroleum industry and by academia. Actually, "sand" and "shale" are terms used to describe grain size rather than mineralogy, and no log provides a direct estimate of grain size. The gamma-ray $\log$, which determines natural radioactive decay of potassium, thorium, and uranium in the formation, provides a measure of clay-mineral abundance if clay minerals are the dominant carriers of these three elements and if clay mineralogy is not too variable. Thus, in a sand/ shale sequence consisting of "clean," mature sands alternating with uniform shales, the gamma-ray log has a boxcar character of alternation between sand and shale baselines. Such a log can be converted to a sand/shale log by drawing sand and shale baselines and interpolating between them. For shale contents of $>30 \%$, a nonlinear interpolation is found to be more accurate than a linear one (Dresser Atlas, 1982); our clay-mineral concentrations are low enough to permit linear interpolation. Shale, of course, consists of a variety of minerals in addition to clay minerals, as well as a variety of grain sizes in addition to clay grain sizes. The baseline approach is naive about these details; it merely identifies locations of similar concentration of radioactive elements.

X-ray diffraction (XRD) analyses of the Leg 146 cores (Westbrook, Carson, Musgrave, et al., 1994) provide an indication of the likelihood that Leg 146 gamma-ray response is proportional to sand and clay-mineral abundances. XRD is, however, only semiquantitative, particularly for relative concentrations of different clay minerals (e.g., McManus, 1991). At all four sites, the coarser grained intervals are composed primarily of quartz and secondarily of plagioclase. These coarser intervals also contain minor amounts of other minerals: potassium feldspar at Site 889 and carbonate at 889 and 892, but probably not enough to obscure the low gamma-ray character of the coarse-grained sediments. Glauconitic sands at Site 892 could contain significant potassium. The Site 891 sands are less mature than those at other sites: they contain significant concentrations of both potassium feldspar and mica. Accordingly, our log-based determination of sand content is less reliable there.

Shipboard XRD estimation of clay mineralogy was not undertaken for Site 888, but for the other three logged sites the dominant clay minerals appear to be illite/mica and chlorite. Chlorite is more abundant than illite/mica at Sites 889 and 892 , whereas illite/mica is dominant at Site 891 . Mixed-layer clays are apparently minor, but the sample preparation techniques may cause them to be underestimated (Westbrook, Carson, Musgrave, et al., 1994). Illite and biotite are very rich in potassium (commonly about $5 \%$ ), chlorite is lower, and mixed-layer clays are quite variable (near zero for montmorillonite). Thus, the intervals highest in clay minerals also may be highest in natural-gamma radiation, especially at Site 891.

The spectral gamma-ray logs run on Leg 146 enable determination of the concentrations of potassium (\%), thorium (ppm), and uranium (ppm) based on the spectrum of observed gamma-ray energies. Westbrook, Carson, Musgrave, et al. (1994) plotted these concentrations as a function of depth. For all sites, these plots show that potassium and thorium exhibit a strong positive correlation, indicating that these two elements are present in the same mineral component-almost certainly clay minerals - and that their variations are proportional to variations in that component. Uranium, in contrast, is inversely correlated with potassium and thorium. Possibly most of the uranium is present in a second component that varies inversely with clay content; alternatively, the spectral inversion for $\mathrm{K}$, Th, and $\mathrm{U}$ is partitioning the three incorrectly within the Leg 146 sites. In many sediments, uranium occupies a component that is present in sufficient quantity to overshadow the uranium concentration of the clays, and consequently Schlumberger provides a "computed gamma ray" (CGR) log that gives only the combined gamma-ray count (in API units) of potassium and thorium. Because uranium here is not a reliable clay-abundance indicator, we used the CGR log rather than the total-gamma log.

We transformed the CGR logs to lithology logs, assuming that clay-mineral abundance variations cause the CGR response to be highest in silty clays, lower in clayey silts, and lower still in sands. We picked baselines for two of these "lithologies" at each logged site, guided by core indications of the overall and local relative abundances of sand, clayey silt, and silty clay. For Site 888, these CGR baselines are 25 for sand and 46 for clayey silt. For Site 892 , the baselines are 9 for sand and 34 for silty clay. For Site 891, these baselines are 40 for sand and 70 for clayey silt; the higher values probably reflect the immaturity of the sands and high illite/mica content of the clayey silts. For Holes $889 \mathrm{~A}$ and $889 \mathrm{~B}$, the upper-slope hemipelagites and turbidites, not surprisingly, appear to have different CGR baselines than the underlying accreted abyssal-plain sediments: clayey-silt and silty-clay baselines are 17 and 34, respectively, for the upper section, and 24 and 40 for the lower section.

In terms of the accuracy of individual values, these CGR-based lithology logs (Fig. 3A) are certainly the least reliable processed logs presented in this paper. They are much more reliable, however, in indicating relative abundance of coarse-grained quartz and clay minerals as a function of depth within each hole. We regard these logs, even for that purpose, as much more useful in showing broad trends than in determining lithology at specific depths. For example, if two intervals have very different clay-mineral compositions, then CGRbased estimates of lithologic difference may be poor in both the absolute and relative sense. Nevertheless, these lithology logs may reveal systematic lithologically induced differences in the relationship between two parameters such as velocity and formation factor, as indicated by separate crossplots for "sands" and "silty clays."

The hole washouts discussed in previous sections indicate poorly consolidated intervals, possibly caused either by intense conjugate fracturing or by the presence of loose sands. The majority of the logged intervals from Sites 889,891 , and 892 are fractured. These caliper logs do not appear to have a strong lithology dependence, and they may reflect variations in fracture intensity instead. At reference Site 888 , in contrast, fracturing is absent and the sediments are mostly underconsolidated. At this site, the caliper log does have a strong lithology dependence, for unconsolidated sands tend to collapse into a hole, forming large-diameter zones. Even a modest concentration of clay minerals tends to "glue" the sediments enough to retard this collapse; poor sorting of sediments has a similar effect.

The intervals of largest hole diameter in Site 888 are confirmed to be sands by both core recovery (although low in sands) and by the gamma-ray log. Applying the same semiquantitative technique as we employed with the CGR logs, we converted the caliper log into an estimate of sand vs. clayey silt. We used baselines of $39 \mathrm{~cm}$ for sand and $27 \mathrm{~cm}$ for clayey silt. Figure $3 \mathrm{~B}$ compares this caliper-based lithology log with the CGR-based one. Considering the uncertainties and very different assumptions in both techniques, the agreement between the two logs is remarkable. A single lithology log based on both data sets is likely to be more accurate than either individual log, so we captured the joint variation in caliper and CGR via principal components analysis (PCA). The first principal component, which accounts for $77 \%$ of the variances in CGR and caliper, is shown in Figure $3 \mathrm{~B}$ as a log of sand vs. clayey silt, based on picking baselines for these two end points. Because the CGR exhibited spurious spikes for three very short intervals (491.5-499.4, 360.3-364.1, and 393.3$397.2 \mathrm{mbsf}$ ), we pasted the caliper-based lithology log into the PCAbased one.

\section{POROSITY FROM DENSITY}

In the discussions and figures of this paper, we follow the ODP convention of designating porosity as a percentage. To avoid confusion when referring to porosity differences, we will use porosity units 

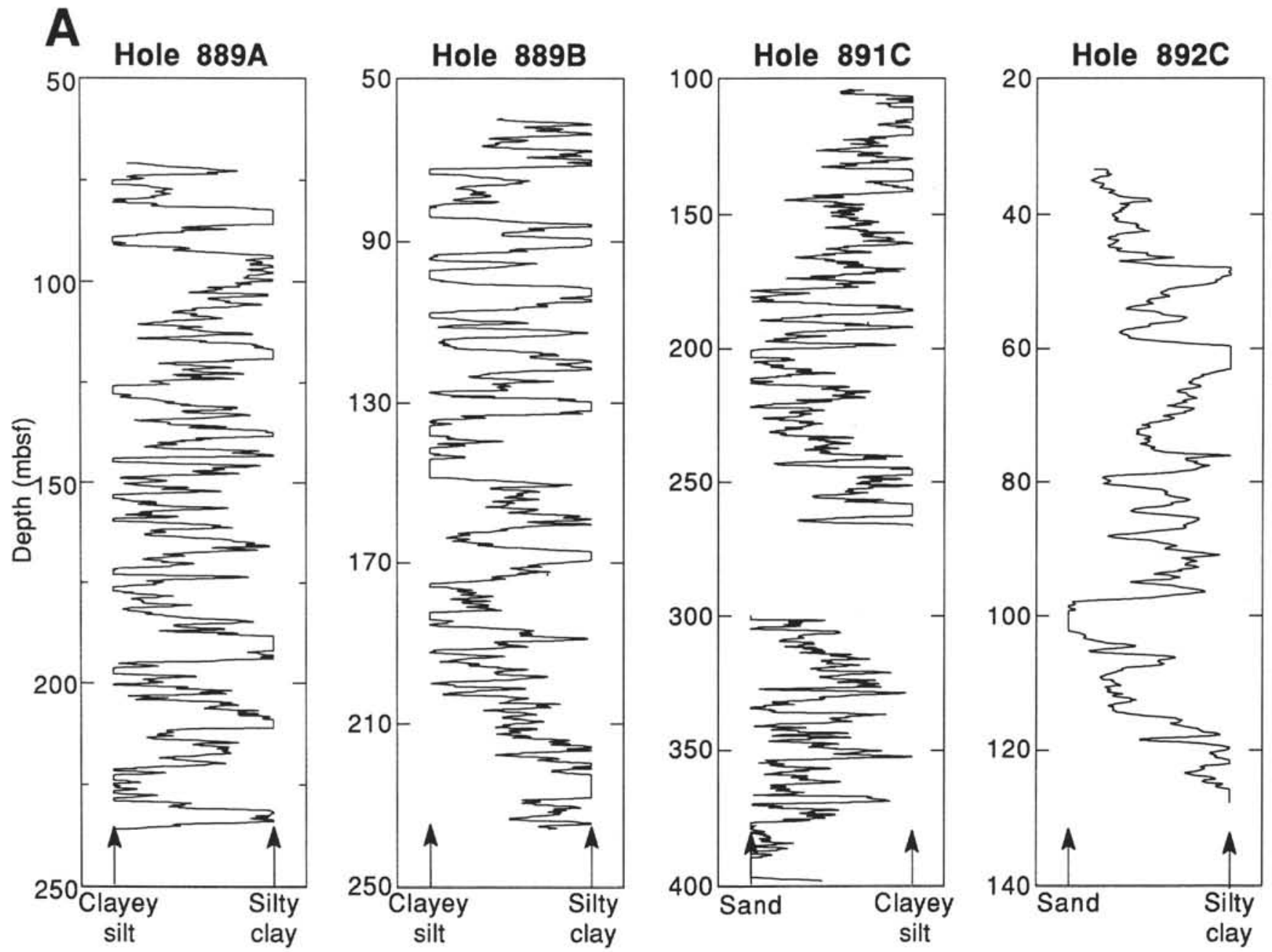

Figure 3. A. Lithology logs for four holes, calculated from the CGR spectral gamma-ray log. B. Comparison of lithology log calculated for Hole $888 \mathrm{C}$ from the CGR spectral gamma-ray $\log$ with one calculated from the caliper. The two are combined in the first-principal-component log at right.

(e.g., porosities of $10 \%$ and $20 \%$ differ by 10 porosity units, not by $10 \%$ ). In all equations, in contrast, we follow the established convention of using fractional porosity.

Bulk density $\left(\rho_{b}\right)$ is a function of fractional porosity $(\phi)$ and of the densities of the two components, rock matrix $\left(\rho_{\text {ma }}\right)$ and fluid $\left(\rho_{f}\right)$ :

$$
\rho_{b}=\rho_{f} \times \phi+(1-\phi) \times \rho_{\mathrm{ma}}
$$

Porosity is by far the dominant influence on bulk-density variations in all sediments except for the lowest-porosity ones. Fluid density is nearly constant and matrix density, which is also referred to as grain density, normally varies by $<10 \%$. Thus, the bulk density log (where reliable) provides a porosity log that is both precise and accurate, if matrix density is known. ODP measurements of index properties determine matrix densities; unlike associated measurements of bulk density and porosity, the calculated values of matrix density are insensitive to core disturbance.

The index measurements of matrix density have both intrasite and intersite variations, caused by both measurement error and lithologic variations. We detected neither systematic downhole variations in matrix density nor correlation of the matrix density variations with our lithology logs, and we therefore assumed constant matrix density within each site. A possible exception is the interval $30-60$ mbsf at
Site 892 , which may be lower in average grain density than other intervals at that site.

We converted the edited bulk-density logs of Figure 1B to porosity logs, using the following matrix densities based on index measurements: $2.88 \mathrm{~g} / \mathrm{cm}^{3}$ at Site $888,2.68 \mathrm{~g} / \mathrm{cm}^{3}$ at Site $889,2.74 \mathrm{~g} / \mathrm{cm}^{3}$ at Site 891 , and $2.62 \mathrm{~g} / \mathrm{cm}^{3}$ at Site 892 . We are, however, somewhat suspicious of the anomalously high matrix densities for Site 888, considering XRD and smear-slide indications of a quartz/feldspar/clay mineralogy at that site. For the high-porosity sediments of Leg 146 in general, an error in matrix density of $\pm 0.05 \mathrm{~g} / \mathrm{cm}^{3}$ causes an error of 2 porosity units.

Figure 4 shows plots of the variation of density-based porosity as a function of depth. Also shown for comparison are neutron-porosity logs. ODP neutron-porosity logs have the poorest signal-to-noise ratio of the geophysical log types considered in this study. In addition, several studies of DSDP and ODP neutron-porosity logs in basalts (Anderson et al., 1985; Broglia and Moos, 1988; Lysne, 1989; Moos, 1990 ) found that these logs consistently overestimate porosity. Broglia and Ellis (1990) used logs from five sites to analyze the relative contributions of several factors to this systematic bias. They concluded that the most important factor is the ODP technique of running the neutron-porosity tool without appropriate eccentralization. Although neutron tools are "compensated" in the sense of applying some correction for tool standoff from the borehole wall, Broglia and Ellis 


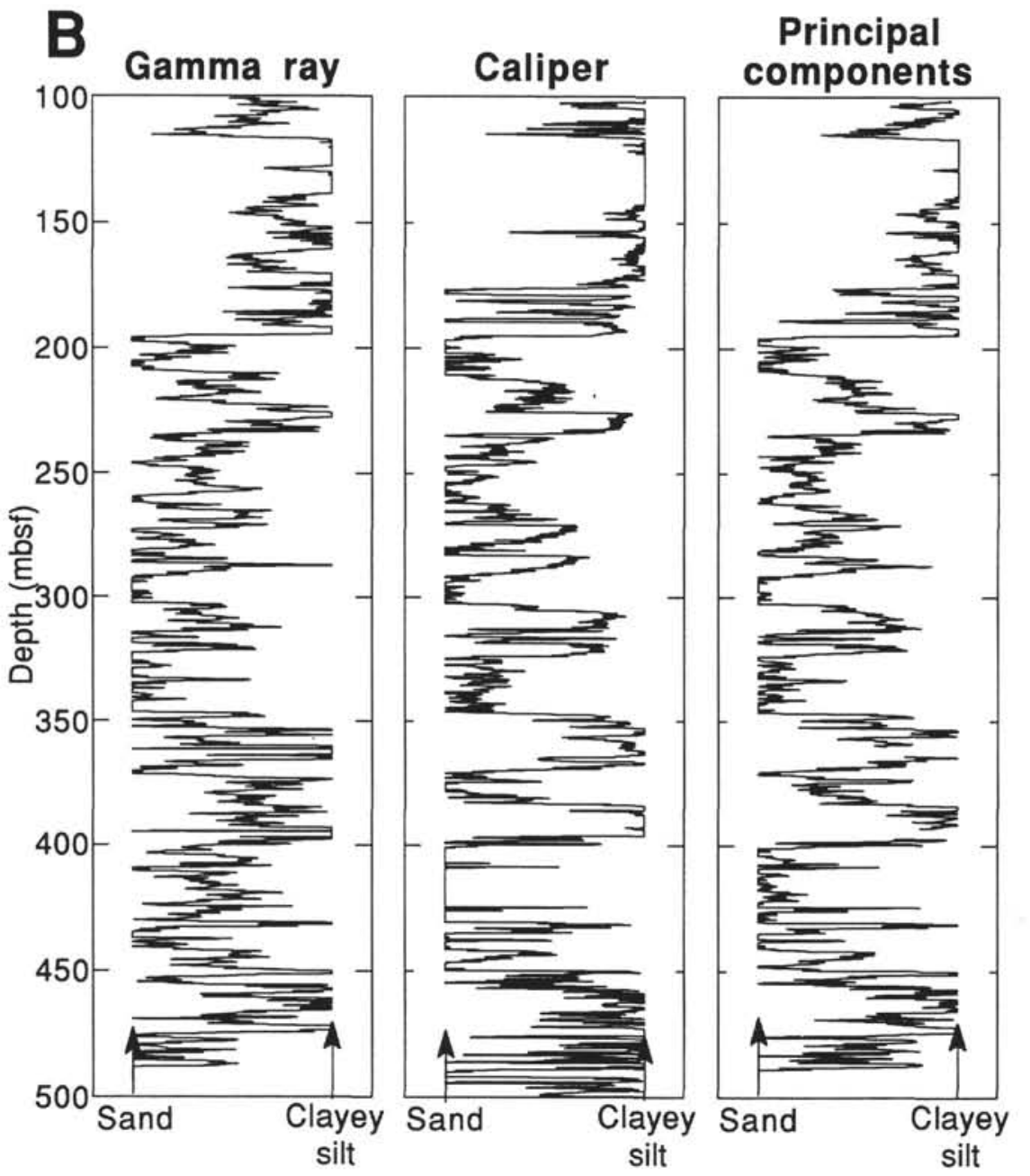

Figure 3 (continued).

(1990) found that this compensation is insufficient for neutron logs that lack eccentralization.

The neutron logs obtained on Leg 146 were run without eccentralization, and the major variations in hole size probably cause some unreliably large porosities. Comparison with density-based porosity (Fig. 4) indicates that the neutron porosities are similar to, or 1-3 porosity units higher than, density porosities. This discrepancy is comparable to the biases detected by Broglia and Ellis (1990) in ODP crustal sites. We conclude that the Leg 146 neutron logs are moderately good, but noisy and perhaps slightly biased, indicators of porosity variations at these sites. Consequently, we used the neutron porosities only for Holes $889 \mathrm{~A}$ and $889 \mathrm{~B}$, because density porosities at these holes are mostly unreliable (Hole 889A) or absent (Hole 889B).

Neutron logs actually respond primarily to hydrogen content, and porosity is calculated assuming that all hydrogen is in the form of pore water. Where clay minerals are present, their bound water causes neutron logs to overestimate porosity, and this effect partly accounts for the discrepancies noted by Broglia and Ellis (1990) and this study. The clay-mineral concentrations of the sediments from Leg 146 sites are, however, quite low-generally only a few percent (Westbrook, Carson, Musgrave, et al., 1994). This concentration is high enough for easy detection by the spectral gamma-ray log but is low enough to cause only a small neutron-porosity bias, probably about one-fourth to one-third of the clay-mineral percentage (e.g., Serra, 1986).
Figure 4 also compares the density and neutron porosities to porosity measurements from core plugs (Westbrook, Carson, Musgrave, et al., 1994). Comparison of porosity logs to core-plug porosities is complicated by several factors. The core-plug measurements may be affected by core disturbance and are certainly affected by non-representative sampling. Sandier intervals were avoided because of core disturbance, and sampling bias is thought to account for systematic differences between index densities and whole-core (gamma-ray attenuation) densities (Shipboard Scientific Party, 1994b). Measurement volumes differ by more than two orders of magnitude. Rebound, the slight expansion of core when moved from in situ conditions to the shipboard laboratory, has a significant effect on porosity: on average, it increases gradually from zero at the seafloor to about 8 porosity units at 500 mbsf (Hamilton, 1979), but its magnitude is substantially reduced by cementation.

We can, however, compare broad trends and averages of log and core-plug porosities. These broad trends are generally consistent (Fig. 4), providing some confirmation of the density-based porosities. Core-plug porosities for reference Site 888 and the upper unfractured portion of Hole $889 \mathrm{~A}$ are equal to or slightly higher than log porosities, possibly reflecting some rebound. For the fractured intervals at Holes $889 \mathrm{~A}, 889 \mathrm{~B}$, and $892 \mathrm{C}$, in contrast, core-plug porosities tend to be equal to or slightly lower than log porosities; rebound is apparently overshadowed here by the fact that the logs detect a large-scale fracture porosity that is unsampled by plugs. The apparent discrepancy between log and core-plug porosities at $60-66$ mbsf in Site 892 is 

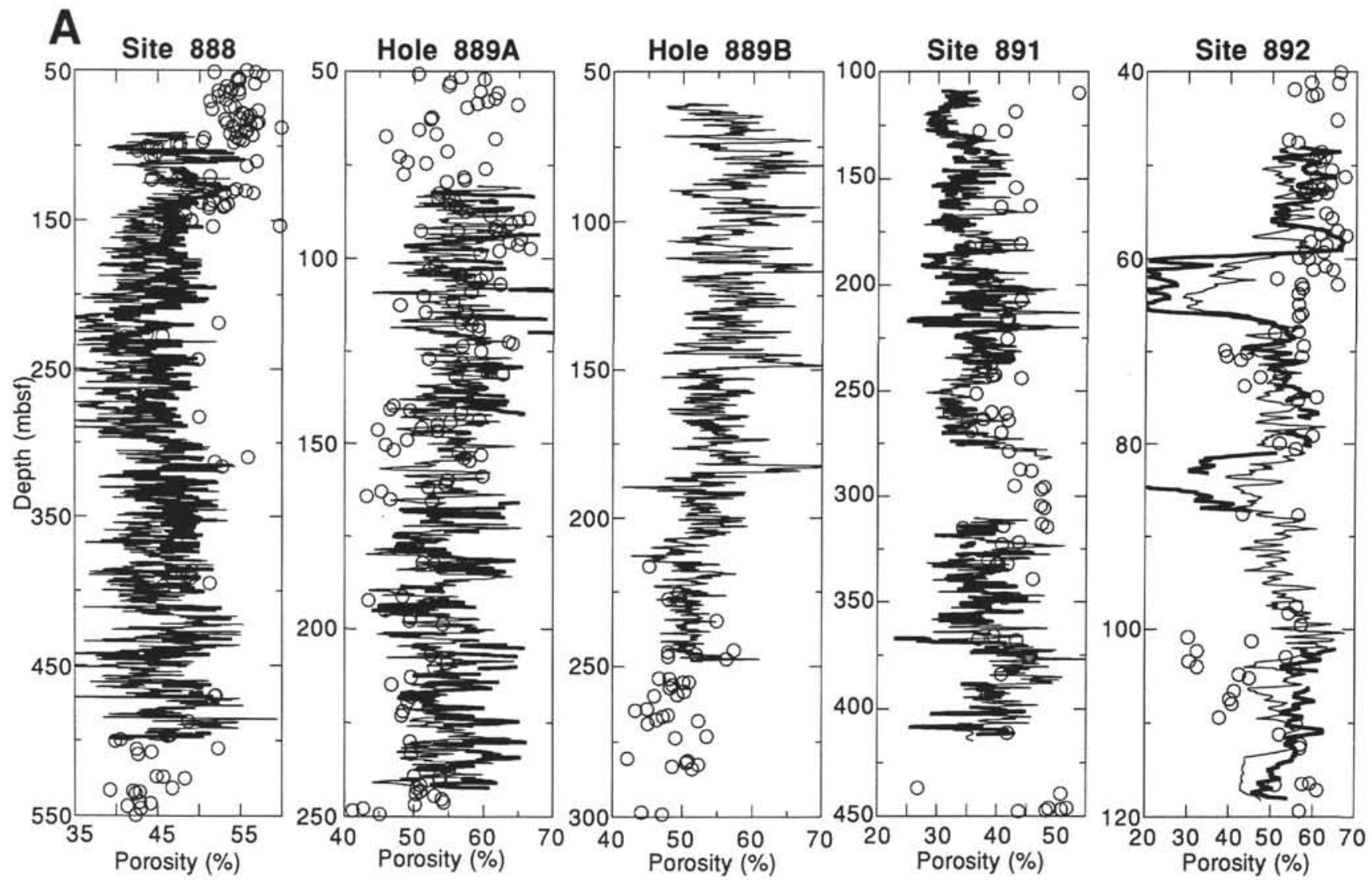

Figure 4. Comparison of three methods of determining porosity at the logged sites. Bold lines $=$ edited density $\log$ from Figure 1 . Light lines $=$ neutron-porosity $\log$. Open circles = index property measurements of Westbrook, Carson, Musgrave, et al. (1994). A. Expanded-scale plots, to facilitate comparison of different data types within each plot. B. Common-scale plots, to facilitate both comparisons among sites and comparison to the resistivity-based porosities of Figure 7A.

probably an artifact of interhole variations in the depth of a highly cemented bed. No coring was undertaken at logged Hole $892 \mathrm{C}$, and the depth of the highly lithified intervals is quite variable between cored Holes $892 \mathrm{~A}$ and $892 \mathrm{D}$. The only surprising discrepancy between core-plug and log porosities is the consistent pattern at Site 891 of higher core-plug than log porosity. Core recovery was only $13 \%$ for this interval, so nonrepresentative plug sampling of the more argillaceous units may account for this discrepancy.

\section{RELATIONSHIP BETWEEN POROSITY AND FORMATION FACTOR}

If clays have a minor contribution to measured formation resistivity $\left(R_{o}\right)$, then $R_{o}$ is related to porosity by the Archie (1942) equation, as generalized by Winsauer et al. (1952):

$$
F F=a \times \phi^{-m},
$$

where the formation factor $F F$ is the ratio of formation resistivity to resistivity of the formation water $\left(R_{w}\right)$ as discussed in a previous section.

Surface conduction on clays can have a significant effect on formation resistivity, particularly at elevated temperatures or at high clay concentrations. Olhoeft (1981) concluded that surface conduction in basalts can be negligible at room temperature but is dominant over pore conductivity at temperatures above $80^{\circ} \mathrm{C}$, far higher than the temperatures reached in Leg 146 boreholes. Where clays are present, observed resistivity $\left(R_{o}\right)$ depends on the contributions of both pore fluids and clay surface conduction, acting as two conductors in parallel according to the relationship (Waxman and Smits, 1968):

$$
1 / R_{o}=F F / R_{w}+B \times C E C \times \rho_{b} \times(1-\phi) /\left(\phi \times \mu^{2} \times F F\right),
$$

where $F F$ is the "intrinsic" formation factor, $B$ is the sodium charge mobility, $C E C$ is the cation exchange capacity, and $\mu^{2}$ is a tortuosity factor. The intrinsic formation factor is the ratio $R_{d} / R_{w}$ that would have been obtained if the formation were saturated with fluid of sufficiently high salinity to permit pore conductivity to dominate clay conductivity. Because the intrinsic formation factor is dependent on porosity according to equation (2), both the pore and clay portions of equation (3) are porosity-related. Given resistivity and density logs, and given estimates of the "constants" $R_{w}, B$, and $\mu^{2}$, one still needs a CEC log before a porosity log can be calculated using equation (3).

In many low-porosity shales and in some low-porosity shaly sands containing hydrocarbons, the clay-conduction component can be comparable in size to the pore-water-conduction component, and neglecting clay conduction can lead to errors in the estimation of water saturation (Waxman and Smits, 1968). Fortunately, the Leg 146 sediments have such high porosities and low clay-mineral contents that clay conduction can be neglected with only minor impact on porosity estimation from formation factor. For example, in an analysis of Labrador Sea sediments that are similar in porosity to, but much higher in clay content than, the Leg 146 sediments, Jarrard et al. 


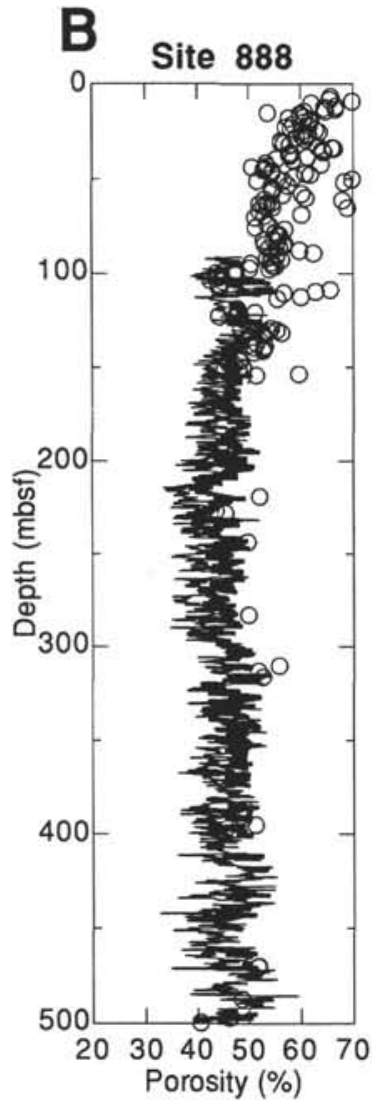

Hole $889 \mathrm{~B}$

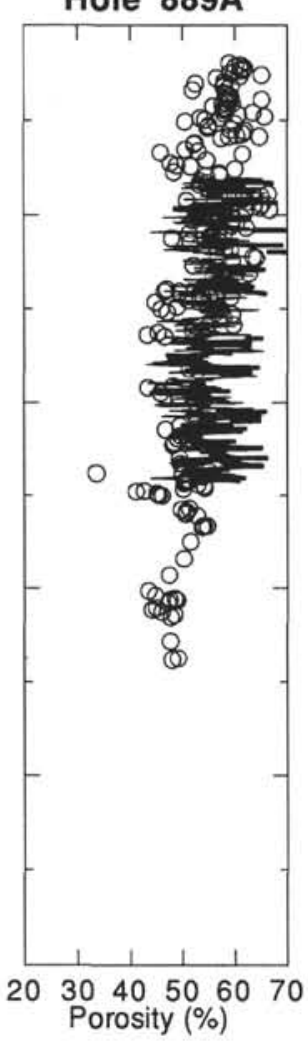

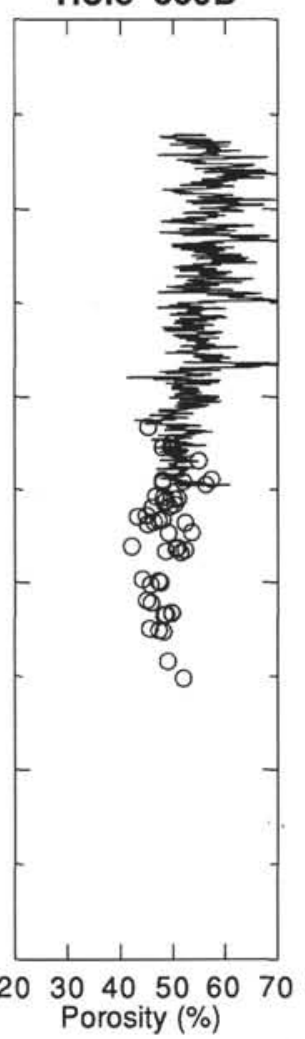

Figure 4 (continued).
Site 891

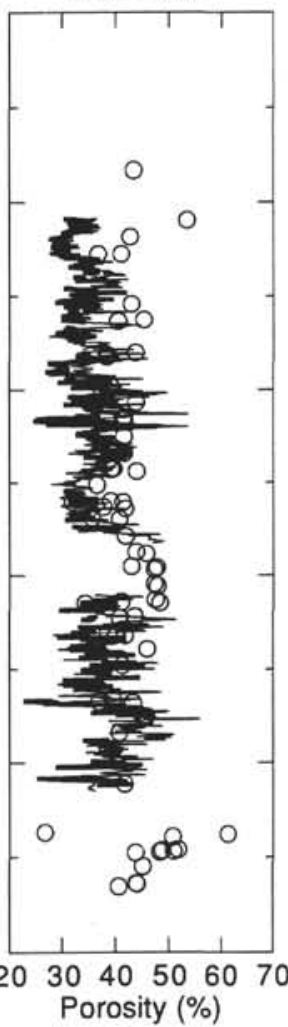

Site 892

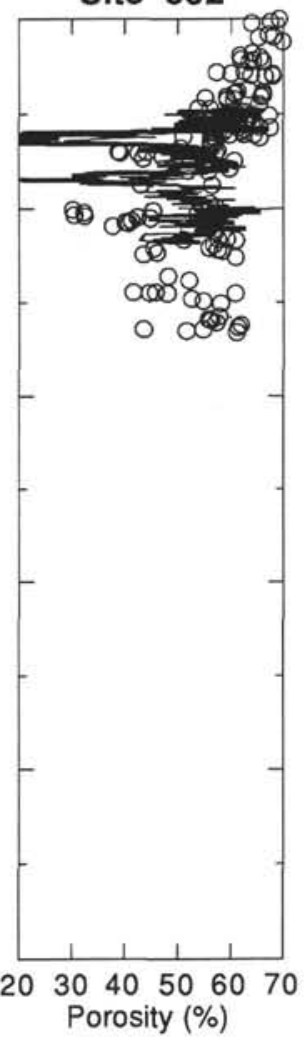

(1989) estimated that neglecting the contribution of clay-surface conduction caused porosity to be overestimated by less than $0.1-0.5$ porosity units.

If an intermittent porosity $\log$ based on density is compared to the $\log$ of formation factor to estimate the coefficients $a$ and $m$, then these coefficients can be used to convert the entire formation factor $\log$ into porosity. Figure 5 plots formation factor vs. porosity for the Leg 146 sites. Also shown on each plot is a best-fit curve, obtained when these data were crossplotted using logarithmic scaling so that the best-fit straight line yields Archie's coefficients $a$ and $m$.

To determine $a$ and $m$, and thereby the relationship between porosity and formation factor, we did not use linear regression for two reasons. First, linear regression assumes that all of the error is in the dependent variable, whereas both variables have substantial errors here. Second, for noisy data such as log crossplots, the choice of dependent and independent variables has a strong effect on the resulting linear trend: the lower the correlation coefficient, the smaller the predicted variation in dependent variable based on variations in the independent variable (i.e., the flatter the trend). Thus if we choose porosity as the independent variable and formation factor as the dependent variable because the former controls the latter, and we use the resulting linear regression equation to predict porosity from formation factor, we will greatly overestimate the variability in porosity; we will underestimate that variability if we reverse dependent and independent variables before regression. With formation factor as the dependent variable, the coefficient $m$ is strongly underestimated by linear regression if the data are noisy.

Instead of linear regression, we used reduced major axis (RMA) analysis to determine the relationship of porosity to formation factor. RMA splits the difference between the regression of $A$ on $B$ and of $B$ on $A$, based on the relative standard deviations of $A$ and $B$, thereby minimizing the effect of dispersion on the slope of the trend. The resulting trend is more like the best-fit line that one would fit by eye than like the flattened trend from regression. Dispersion from the trend is not assumed to be due entirely to one of the two variables; thus, RMA treats log dispersion more realistically than does regression, although principal components are even better in this regard. Finally, the same equation can be used for predicting formation factor from porosity as for predicting porosity from formation factor.

Comparison of companion porosity/formation-factor plots using neutron vs. density logs for porosity shows that dispersion is almost always lower for the density-based plot than for the neutron-based one. The exception is Hole $889 \mathrm{~A}$, which has the poorest and most heavily edited density log (Fig. 1). At this site, the neutron-porosity crossplot is far superior to the density-porosity one for the upper hemipelagic interval; in the lower interval, in contrast, the two gave similar correlation coefficients $(R=-0.38$ and -0.40 , respectively), but the slope $m$ was more plausible for neutron than for density $(\mathrm{m}=$ 1.58 and 1.15 , respectively). Given also that we had no density log at all for Hole 889B, we decided to use neutron porosity for both holes at this site. For the upper interval at Hole $889 \mathrm{~B}$, however, the neutron porosity gave an unacceptably large dispersion (Fig. 5), so we used the values of $a$ and $m$ determined for the same section of adjacent Hole 889A.

The depth intervals chosen for analysis in Figure 5 are based partly on the lithostratigraphic units of Westbrook, Carson, Musgrave, et al. (1994). For Holes 889A and 889B, we plotted separately the upper slope sediments, which were deposited in situ, and the lower sediments, which were deposited on the abyssal plain and later consolidated and fractured by prism deformation. Hole $892 \mathrm{C}$ is short and 

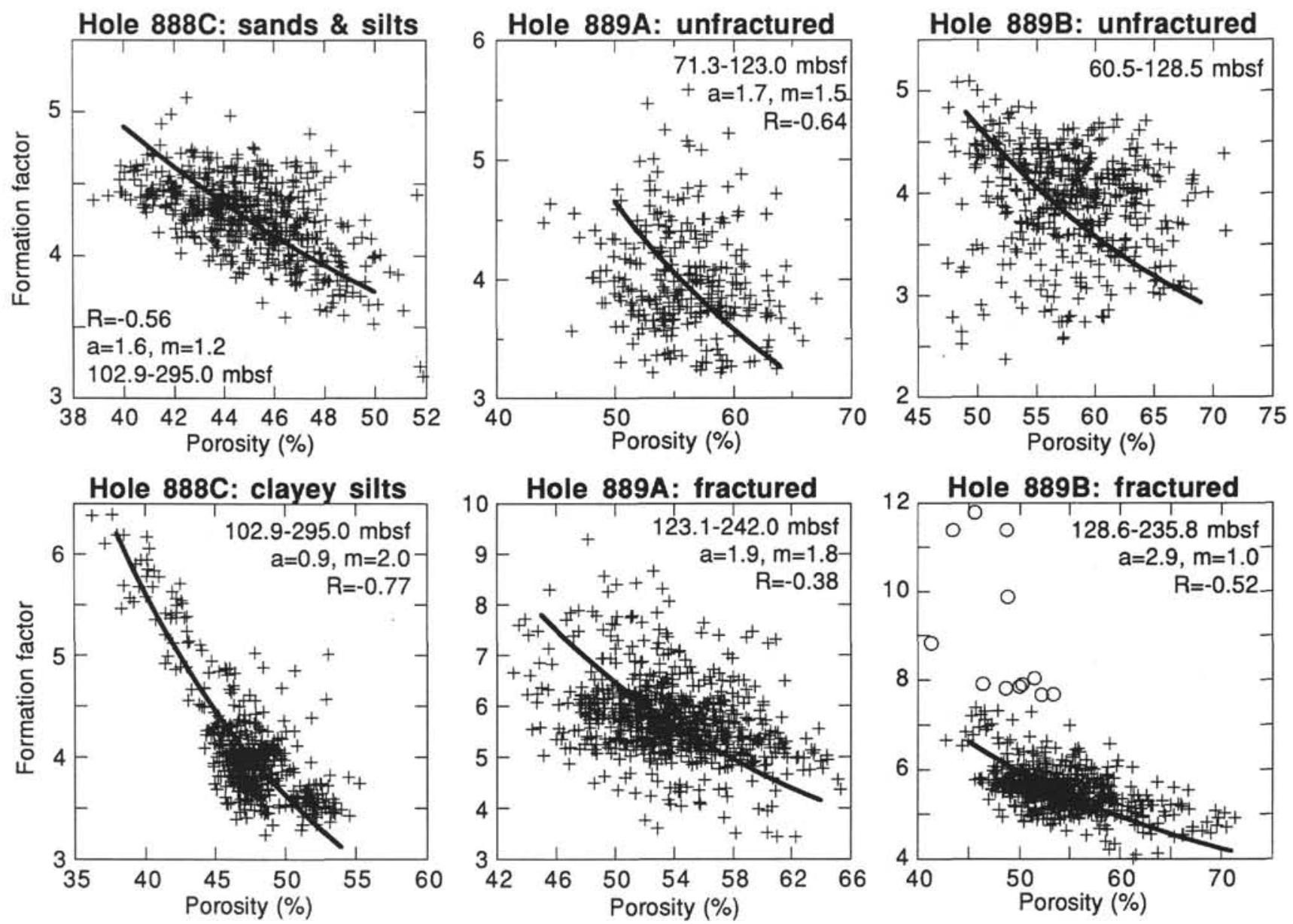

Figure 5. Crossplots of formation factor vs. porosity for different lithologies (Site 888) or for different structural domains (Sites 889 and 891 ). Porosity for Sites 888,891 , and 892 is determined from edited density logs; that for Holes $889 \mathrm{~A}$ and $889 \mathrm{~B}$ is based on the neutron-porosity log. Lines and their coefficients are based on reduced major axis (RMA) analysis. Open circles = points excluded from RMA fit. Each plot is at the highest resolution possible for its data range; consequently, axes' ranges differ among plots.

consists of only one lithostratigraphic unit. For Hole $888 \mathrm{C}$ we combine Units I and the upper part of Unit II, but we exclude the interval beneath 295 mbsf because it substantially degrades the pattern evident above that depth. Below $295 \mathrm{mbsf}$, velocity and formation factor indicate continued porosity decrease, yet the density and neutron logs indicate porosity increase (Westbrook, Carson, Musgrave, et al., 1994). Our confidence in the reliability of the former group of measurements is higher than it is for density and neutron logs; in the final section of this paper we discuss a possible explanation of this discrepancy.

Hole $891 \mathrm{C}$ exhibits little lithostratigraphic variation downhole; instead, it is divided into subunits based on structural variations: (1) an upper folded zone with little fracturing (our 104.8-198 mbsf plot), (2) a zone with increasing fracturing and lithification (our 198-271 and 302-369 mbsf plots, broken here into two subzones at the gap between upper and lower logging runs), and (3) a return to less consolidated and fractured sediments (369-423.7 mbsf) beneath the frontal thrust, interpreted to be at 375 or $384 \mathrm{mbsf}$ in cores and at $369 \mathrm{mbsf}$ in the logs. Breaking Hole $891 \mathrm{C}$ into four intervals has an added advantage: this site has a poorly known thermal gradient and therefore, the gradual downhole change in fluid resistivity may be incorrectly estimated. By breaking the log into four intervals, we prevent possible errors in thermal gradient from dominating or obscuring the relationship between porosity and formation factor; we do not, however, prevent some bias to the coefficients $a$ and $m$. For example, if the estimate of thermal gradient is changed from $60^{\circ}$ to $50^{\circ} \mathrm{C} / \mathrm{km}$, the cor- relation coefficients change by $₫ 0.03$, estimates of $a$ change by $₫ 0.4$, and estimates of $m$ change by $\leq 0.03$.

We used Z-plots to examine the possibility of lithology-dependent differences in the pattern between porosity and formation factor. $Z$-plots are crossplots in which the value of a third $(Z)$ variable is indicated by the symbol or color of each plotted point. Each Z-plot of porosity vs. formation factor selected among five different colors for each point, based on the clay content indicated by the lithology log. None of the accretionary prism intervals showed a significant lithology dependence to the relationship between porosity and formation factor, but such a difference was found in reference Site 888 (Fig. 5).

In undeformed sediments such as at Site 888 , one expects the tortuosity of interconnected pores to be relatively low for sands, but higher for poorly sorted clayey silts because of the clogging of pore throats by finer particles. Consequently, an electric current flows more easily through the open network of pores in a sand than through the more convoluted pore network of a clayey silt of comparable porosity, and the resistivity and formation factor of the latter are higher. This prediction is confirmed by the plots (Fig. 5) for two lithologies of Site 888: sands and silts (the left two-thirds of the PCA lithology $\log$ of Fig. 3B) and clayey silt (the right one-third).

With increasing consolidation accompanied by intense fracturing, which characterizes the prism sediments, intergranular differences between sandier and shalier sediments may be obscured by high-conductivity electrical pathways through fractures. The effects of neglecting unresolved lithology-dependent differences in the porosity/ 

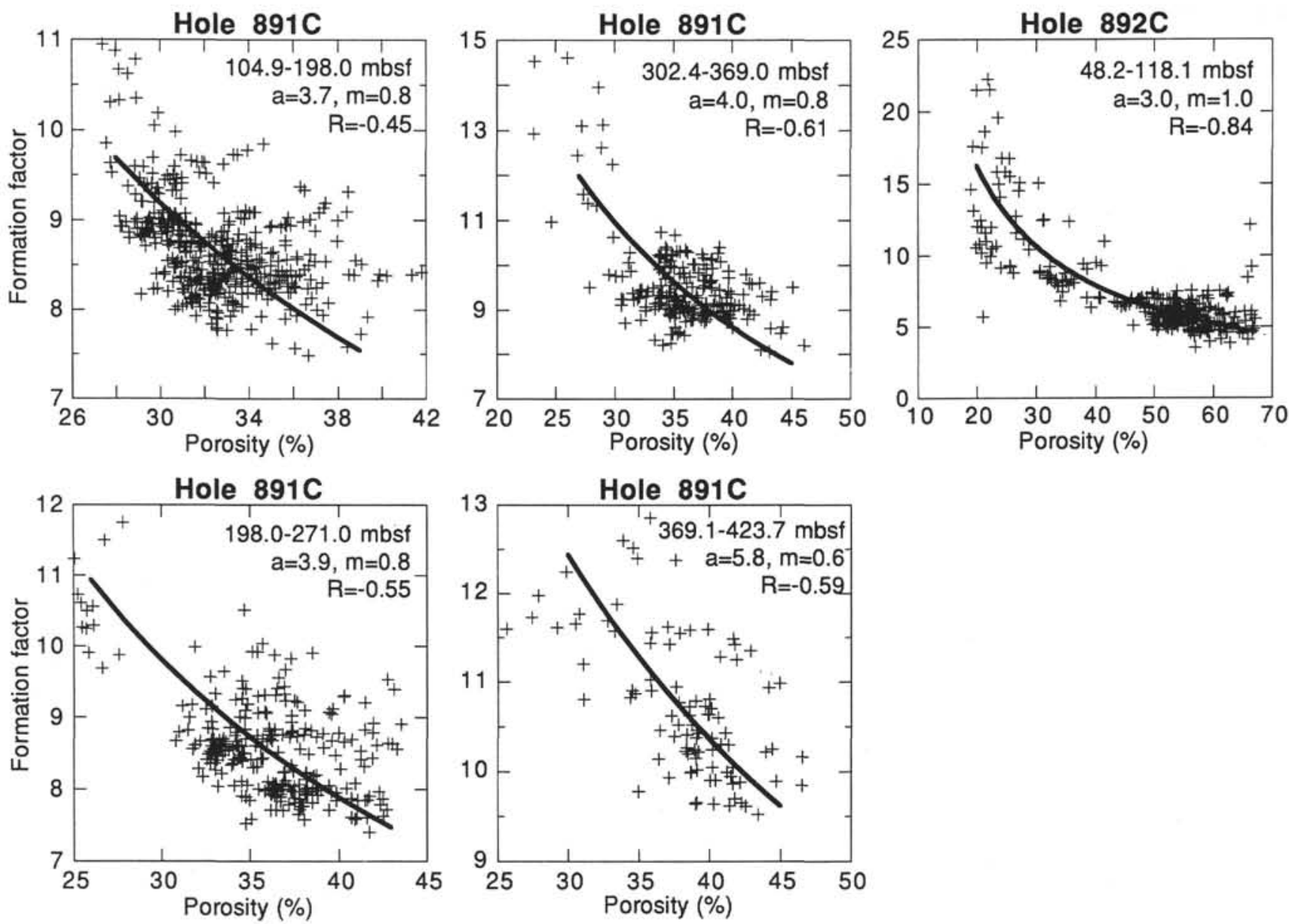

Figure 5 (continued).

formation-factor relationships are twofold. First, we may incorrectly estimate the porosity contrast between different lithologies. Second, we underestimate $m$, by not detecting the presence of parallel trends on the crossplot.

The RMA estimates of $a$ and $m$ are shown on the crossplots of Figure 5. In general, we find that $a$ is about $1-4$ and $m$ is about 1-2. Based on a large body of core and log data for low-porosity sandstones and limestones studied by the petroleum industry, $a$ is usually found to be about $0.8-1.2$ and $m$ is about 1.8-2.0 for unfractured rocks; $m$ moves toward 1.0 with increasing dominance of interconnected-fracture porosity. For uncemented high-porosity sediments, in contrast, Jackson et al. (1978) suggested that $a \approx 1$ and that $m$ depends on grain shape: $m \approx 1.2$ for spheres and $m \approx 1.9$ for platy shell fragments. Jackson et al. (1993) found log-based values of $m$ ranging from 1 to 2 in high-porosity carbonates with widely varying diagenetic histories. Keller (1982) generalized that $a \approx 1.88$ and $m \approx 1.37$ in weakly cemented detrital rocks with fractional porosities of 0.25 0.45 , but we are not aware of any $\log$-based estimates of $a$ and $m$ for high-porosity silty clays and clayey silts such as those studied here. Some of our values of $m$ are anomalously low-particularly the values of about $0.6-0.8$ for Hole $891 \mathrm{C}$. These discrepancies may be caused in part by the inability to determine separate trends for different lithologies and in part by uncertainties in fluid resistivities.

Our estimates of $a$ and $m$ are quite different from those obtained by shipboard analysis of core plugs. That analysis followed Wang et al. (1976) in assuming that $m=1.76$ and estimating only the intercept $a$ from regression of formation factor on porosity. Calculated values for $a$ ranged from 1.44 for Site 888 to 2.07 for Site 889 ; the correlation coefficients of $0.49-0.87$ are comparable to the log-based ones of Figure 5. The core-based and log-based methods are subject to quite different assumptions and uncertainties. It is not even clear that the two methods should agree, because the control exerted by fracturing on electrical conductivity is very different at the meter scale in situ than at the millimeter and submillimeter scale in core samples.

Our analysis relies not on interpretation of the coefficients but on using the correlations of Figure 5 to convert between formation factor and porosity. We have used these RMA equations to convert the formation factor logs to porosity, and we consider these resistivity-porosity logs to be our most reliable estimates of porosity variations at the Leg 146 sites. Signal-to-noise ratio is higher for these logs than for density-based porosity and much higher than for neutron-based porosity. These logs are much more complete than density-based porosity logs. They are much less likely to be biased by hole problems than either the density or neutron porosity logs. The weakness of resistivity logs-their need for calibration to known porosities-has been adequately addressed by crossplots vs. the subset of relatively reliable density-based porosities.

Figure 6 summarizes, at a common scale, the porosity/formationfactor trends established by RMA and previously shown in the crossplots of Figure 5. The unfractured sediments of Sites 888, 889, and 891 form a reasonably tight grouping of trends. The subtle difference between sands and clayey silts at Hole 888 is evident in Figure $6 \mathrm{~A}$ only at low porosity, where the presence of even a small amount of clay minerals apparently blocks current flow. At higher porosities, or where fracturing also affects electrical conductivity, we see no lithologic difference. The trends for the upper parts of Holes 889A, 889B, and $891 \mathrm{C}$ lie above the Site 888 trends, possibly indicating that slumping and folding in the former sites has raised the formation fac- 

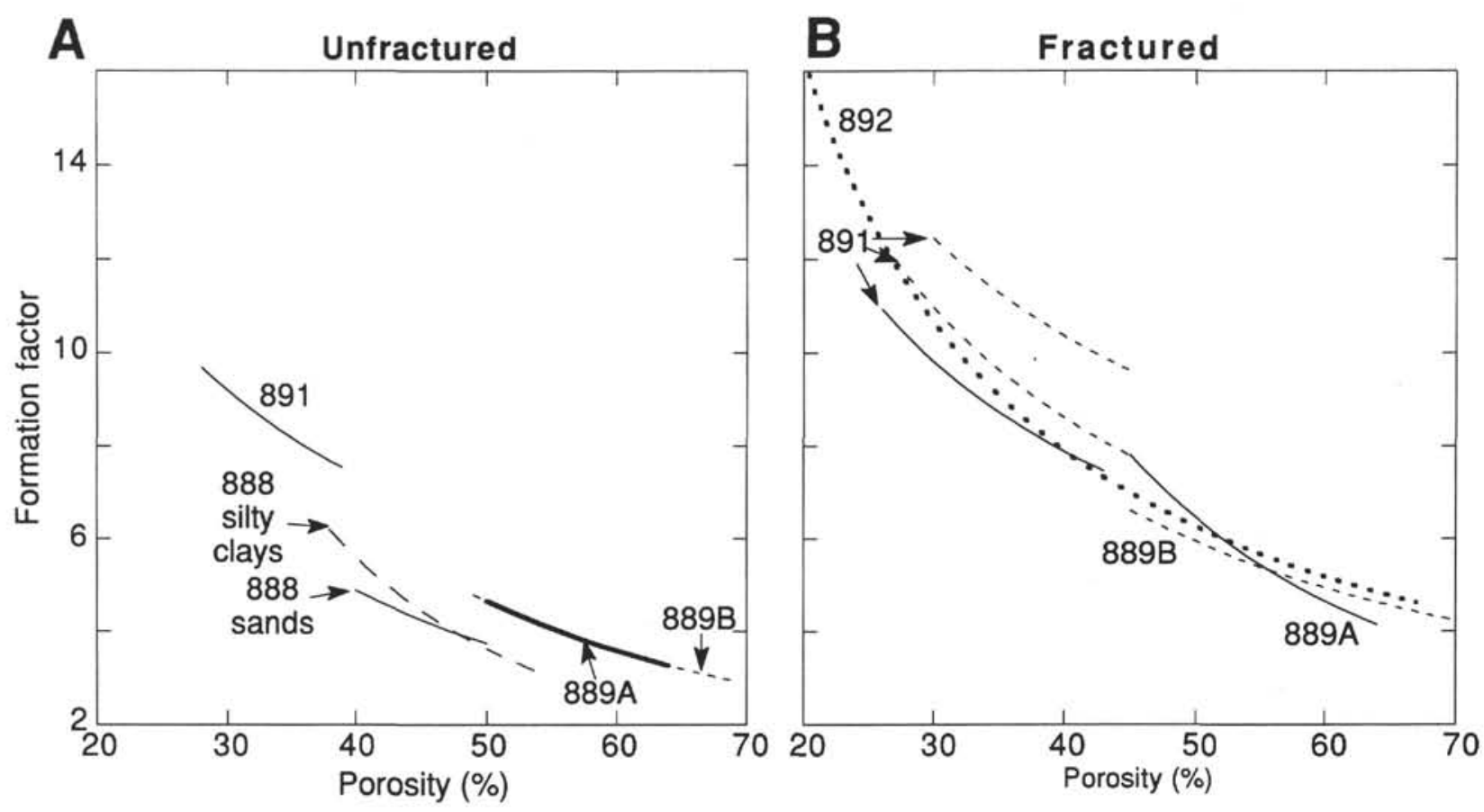

Figure 6. Summary of the relationships between formation factor and porosity shown by the curve fits of Figure 5. Both unfractured rocks (A) and fractured rocks (B) show similar patterns among different intervals and sites. For a given porosity, formation factor is much higher in fractured rocks than in unfractured ones, probably because the latter are much less cemented.

tor. The difference, however, is neither large enough nor present at enough locations to isolate deformation as the cause.

Deformation clearly does have a large effect on the porosity/formation-factor relationship when it progresses to pervasive fracturing. Compared to the unfractured intervals of Figure $6 \mathrm{~A}$, the fractured ones of Figure $6 \mathrm{~B}$ have the same overall porosity range but much higher formation factors for a given porosity. For the four segments of Site 891, one observes an apparently systematic downhole change in the porosity/formation-factor trends: they are approximately parallel, but deeper intervals have higher formation factor for a given porosity. Some caution is required in interpreting downhole changes in formation factor at Site 891, however, because of the lack of in situ temperature data. Conceivably, a much lower thermal gradient than assumed could account for this pattern, but we will see in a later section that the same pattern is found between sonic traveltime and porosity. The average pattern for fractured rocks at Site 891 is confirmed by the three other holes with fractured intervals.

Different relationships of formation factor to porosity, and particularly different values of the slope $(\mathrm{m})$, are expected for fractured and unfractured rocks. The substantial changes seen in Figure 6 are not simply a slope effect; instead, they reflect the very different types of porosity. The unfractured sediments included here have very high porosities because consolidation and cementation have not progressed very far. They have, however, progressed far enough for clay-rich intervals to be less porous than sandier intervals at all sites except Site 888. In contrast, the porosities in the fractured rocks are comparable to those in unfractured rocks only because of the combination of two types of porosity. Intergranular porosity is moderate, but the electrical connectivity associated with this type of porosity is probably very low because these sediments have been strongly consolidated and in many cases partly calcite-cemented. Electrical current flow through the network of numerous open fractures, in contrast, is presumably relatively easy. We cannot estimate the relative proportions of these two types of porosity in the fractured prism rocks, but we can qualitatively see their relative contributions to electrical conductivity in the pattern of Figure 6. Compared to unconsolidated rocks of comparable porosity, cementation and consolidation are more important to formation factor than are open fractures.

\section{POROSITY VARIATIONS WITH DEPTH}

Porosities determined from formation factor are plotted as a function of depth in Figure 7A. These porosities are generally similar to, or slightly lower than, the neutron porosity logs of Figure 4. As previously discussed, the neutron logs overestimate porosity slightly at hole washouts and clay-rich zones. Average porosities in Figure 7A are, of course, similar to average density-based porosities in Figure 4, because they are calibrated to density porosities. Comparison of the porosity logs of Figure 7A to core-plug porosities (Fig. 4) is subject to the same uncertainties previously described for comparing coreplug porosities to density and neutron porosities, and the results of that comparison are generally similar to those already discussed.

For the interval below 275 mbsf at Site 888, the porosities shown in Figure 7A are substantially less than either density-based or neutron porosities. This interval shows a clear compaction pattern in the formation factor and sonic logs, but no compaction pattern in density and neutron logs. For this interval we calculated porosity by applying the relationship between density porosity and formation factor of the overlying interval to the formation-factor log of the lower interval. We note, however, that this procedure underestimates porosity if the density and neutron logs are correctly indicating absence of a compaction pattern in the deeper interval.

Hamilton (1976) compiled porosity/depth trends for marine sediments of different lithologies. His empirical curve suggests that porosities of "terrigenous" sediments are about $71 \%$ at the seafloor, $53 \%$ at $250 \mathrm{mbsf}$, and $30 \%$ at $500 \mathrm{mbsf}$. Porosities are extremely sensitive to clay-mineral content, however, and Hamilton (1976) did not consider this variable. Brückmann (1989) determined separate empirical porosity/depth trends for sands, clayey silt, and silty clay that 
reflect this difference. His seafloor porosities are $61 \%$ for sands and clayey silts and $67 \%$ for silty clays, and his estimates of porosity at $250 \mathrm{mbsf}$ are $48.5 \%, 52 \%$, and $58 \%$, respectively.

At depths of 1 or more kilometers, the initially randomly oriented clay-mineral grains have compacted to a nearly parallel configuration, so clay-rich sediments are actually substantially lower in porosity than sandier sediments. The curves of Brückmann (1989), however, do not show any evidence of this convergence and crossover within the top $600 \mathrm{mbsf}$.

Figure 7B separates the Site 888 porosity/depth trends by lithology. With this binary lithologic split, the porosity distinction between sands and clayey silts is subtler than that suggested by Brückmann (1989): porosities are virtually the same at shallow depth, and they diverge by $2-4$ porosity units below $350 \mathrm{mbsf}$. A better way to examine the effect of clay content on porosity is by examining the small-scale character of the lithology and porosity logs. Reference Site 888 exhibits the normal positive correlation between clay content and porosity, but every other hole logged on Leg 146 exhibits an inverse correlation, as evidenced by log character on the 1-40-m scale (Westbrook, Carson, Musgrave, et al., 1994). This inverse correlation indicates differential compaction of these prism sediments, caused either by deep burial followed by exhumation or by horizontal stress.

The porosity logs of Figure 7A exhibit dramatic intersite variations in their consistency with the empirical trends. Reference Site 888 is substantially lower in porosity than the Brückmann (1989) and Hamilton (1976) predictions for the entire logged interval above 450 mbsf, in spite of core-based conclusions that these sediments are underconsolidated due to a very high sedimentation rate. At $150 \mathrm{mbsf}$, predicted porosities are 7-12 porosity units higher than observed; by $250 \mathrm{mbsf}$ this difference is reduced to $2-7$ porosity units. Unfractured reference sediments at Holes $889 \mathrm{~A}$ and $889 \mathrm{~B}$, above the contact with underlying fractured sediments at $123-128 \mathrm{mbsf}$, are only slightly lower in porosity than predictions.

Porosities of the highly fractured prism sediments at Holes 889A and $889 \mathrm{~B}$ agree very closely with the predictions by Hamilton (1976) and Brückmann (1989) for normally compacted sediments. For Hole $892 \mathrm{C}$, the logged interval is too short for a diagnostic comparison to porosity/depth trends, but the observed segment is broadly consistent with, or 5-10 porosity units lower than, the empirical trends. By far the largest discrepancy between observed and predicted porosity/ depth trends is found at Hole $891 \mathrm{C}$, at which porosities actually increase with depth, based on core plugs and on neutron, density, and resistivity logs (Figs. 4 and 7A). Our observed porosities of $30 \%-$ $35 \%$ in the top $75 \mathrm{~m}$ of the logged interval contrast with predicted porosities of $50 \%-60 \%$. Core porosities in this upper interval are closer to, but still substantially less than, predictions. Higher porosities, typical of normally compacted sediments, are observed only beneath the frontal thrust, visible in log responses at about $369 \mathrm{mbsf}$.

The porosity/depth trends of these four sites show no simple and systematic pattern of shallow porosity either decreasing (Bray and Karig, 1985) or increasing (Hyndman, Wang et al., 1993) as sediments are incorporated into an accretionary prism and the section is cumulatively thickened. Instead, porosity variations reflect a more complex relationship between accretion and porosity change. To investigate that pattern, we first must examine the dependence of velocity on porosity.

\section{RELATIONSHIP BETWEEN POROSITY AND VELOCITY}

\section{Expectations}

The controls on compressional sound velocity (or its inverse, sonic traveltime) are well established for porous rocks (Gassmann, 1951): velocity depends on porosity, bulk density, and elastic moduli (frame bulk modulus, bulk moduli of minerals and fluid, and shear modulus). Pore aspect ratio also affects velocity, particularly where the aspect ratio is high, as in microfractured rocks (Toksöz et al., 1976). Unfortunately, the elastic moduli are seldom known, so these theoretical transforms are of limited general usefulness.

For low-porosity rocks of a variety of mineralogies, the empirical porosity/traveltime relationship of Wyllie et al. (1956) has proven to be successful in the oil industry for almost half a century. The Wyllie et al. (1956) "time-average" relationship is:

$$
\phi=\left(\Delta \mathrm{t}_{r o c k}-\Delta \mathrm{t}_{m a}\right) /\left(\Delta \mathrm{t}_{f}-\Delta \mathrm{t}_{m a}\right)
$$

where $\Delta \mathrm{t}_{\text {rock }}$ is the traveltime (in $\mu \mathrm{s} / \mathrm{ft}$ ) in a porous rock, $\Delta \mathrm{t}_{\mathrm{ma}}$ is the matrix, or zero-porosity, traveltime, $\Delta \mathrm{t}_{\mathrm{f}}$ is the traveltime of the pore fluid, and $\phi$ is the fractional porosity. Velocity $\left(V_{p}\right.$, in $\left.\mathrm{km} / \mathrm{s}\right)$ is related to traveltime $(\Delta \mathrm{t})$ by:

$$
\mathrm{V}_{p}=304.8 / \Delta \mathrm{t}
$$

The Wyllie time-average equation, though empirical, is conceptually plausible: it assumes that the traveltime of sound in a porous rock is equal to the time spent moving through a corresponding volume of fluid, plus the time spent moving through a corresponding volume of zero-porosity rock. Unfortunately, Wyllie's equation is reasonably accurate only for the generally low porosities of interest in the oil industry. For porosities higher than about $25 \%$, this equation greatly overestimates porosities. By using a locally calibrated apparent matrix traveltime, however, one can extend the usefulness of this equation somewhat beyond $25 \%$ porosity.

Wood (1941) simplified the theoretical Hookean elastic equations (e.g., Gassmann, 1951), by assuming that the rock medium lacks rigidity and thus both rigidity modulus and skeletal bulk modulus are zero. His resulting relationship between velocity and porosity predicts much lower velocities than does Wyllie's at a given porosity. At best, this relationship can be expected to be appropriate only at very high porosities (e.g., $>60 \%$ ).

Raymer et al. (1980) attempted to bridge the gap between the lowporosity usefulness of the Wyllie et al. (1956) relationship, where sound transmission is matrix-supported, and the very-high-porosity usefulness of Wood's (1941) relationship, where fluid-supported behavior is observed. Raymer et al. (1980) concluded that traveltime increases dramatically within the transition zone, and that this transition occurs at porosities of $35 \%-45 \%$. Unfortunately, Raymer et al. (1980) had only sparse data for porosities above $35 \%$. In our tests of the Raymer relationship using high-porosity data from ODP and DSDP, we have found it to have poor predictive ability (Jarrard et al., 1989; Fulthorpe et al., 1989; Jarrard and Symonds, 1993).

Nobes (1989) found that a simple average of the Wyllie and Wood relationships was quite successful for core-plug data:

$$
\Delta \mathrm{t}=\phi \times \Delta \mathrm{t}_{\text {Wood }}+(1-\phi) \times \Delta \mathrm{t}_{\text {Wyllie }} .
$$

The Nobes (1989) relationship was developed from a database of DSDP core analyses of clay-rich sediments, spanning the porosity range $10 \%-90 \%$, and tested successfully on carbonate-rich sediments drilled on ODP Leg 114 (Nobes et al., 1991). As discussed later, however, core-plug velocities on unconsolidated sediments are untrustworthy indicators of in situ velocities. This relationship also fits some log data for pure carbonates (Jackson et al., 1993), but the relationship between porosity and velocity is so variable within highporosity carbonates that no universal relationship is feasible (Urmos et al., 1993; Jarrard and Symonds, 1993). Even volumetrically minor carbonate diagenesis can substantially increase rigidity and therefore velocity, without affecting porosity significantly. In contrast, carbonate diagenesis is generally less important for porosity/velocity relationships among terrigenous sediments. At least in the top few 


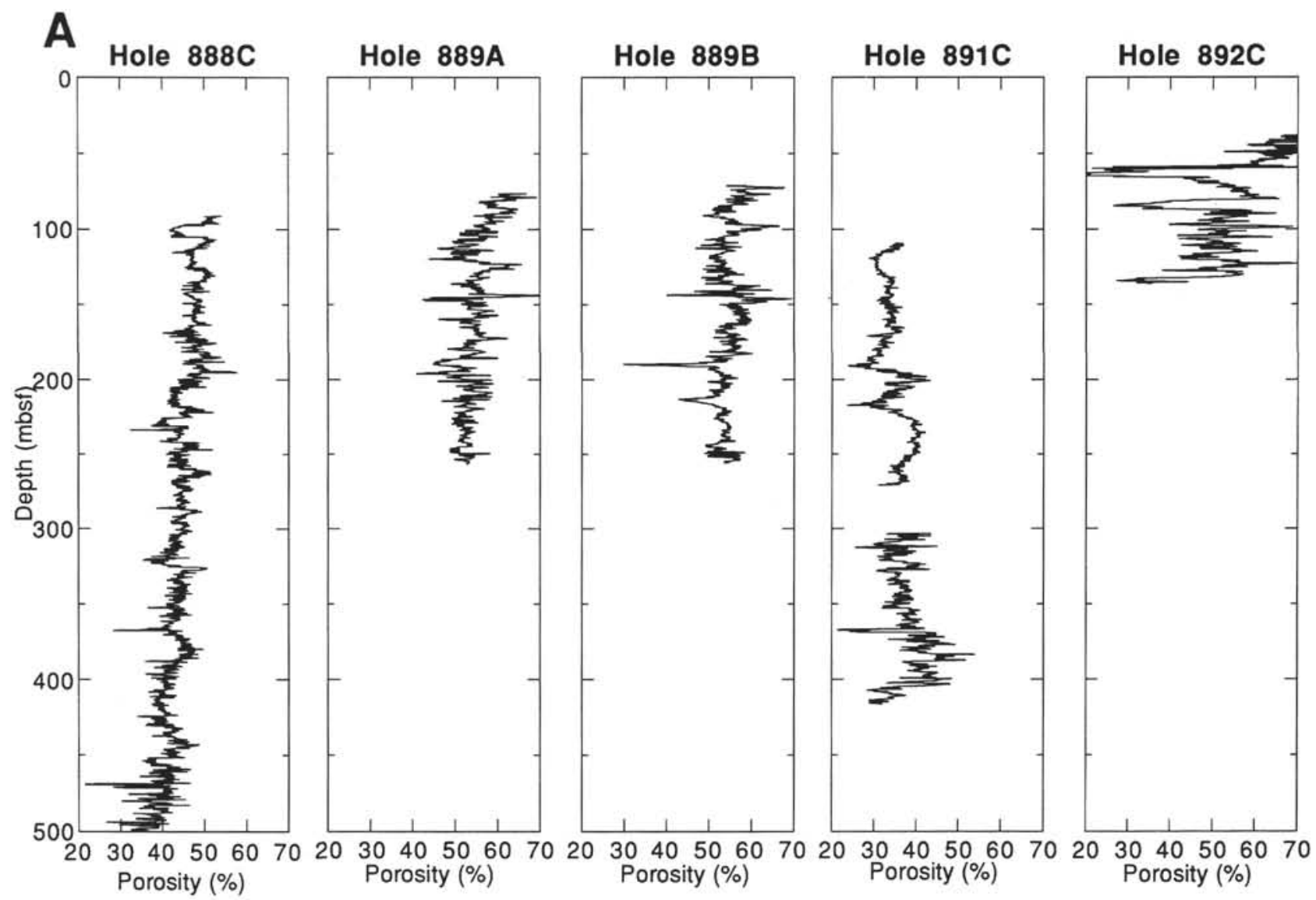

Figure 7. A. Porosity logs for all logged sites, calculated from resistivity logs by applying the conversions (Fig. 5) from formation factor to porosity. B. Comparison of sand and clayey silt porosities for Site 888, based on the porosity log of Figure 7A and the PCA lithology log of Figure 3.

hundred meters of such sediments, mechanical compaction usually dominates both porosity and velocity change, and the crucial controls on mechanical compaction are grain-size sorting and clay-mineral content.

Several authors (Castagna et al., 1985; Han et al., 1986; Tosaya and Nur, 1982) have examined the combined effects of clay content and porosity in controlling compressional and shear velocities in sandstones and shaly sandstones. Velocity decreases progressively with both increasing porosity and increasing clay content, and Castagna et al. (1985) found that a very small concentration $(<3 \%)$ of clay minerals is sufficient to significantly decrease velocity by reducing elastic moduli. Unfortunately, the focus of these three studies was on the low porosities of most interest to the petroleum industry: $2 \%-$ $30 \%$ (Han et al., 1986), 0\%-20\% (Tosaya and Nur, 1982), and about $2 \%-23 \%$ (Castagna et al., 1985). Consequently, extrapolation to the porosity range of this study would be hazardous. Hyndman, Moore, et al. (1993) merged the relationship of Han et al. (1986) for low porosities with the pattern that Jarrard et al. (1989) found for high-porosity $(34 \%-57 \%)$ silty clays and clayey silts of the Labrador Sea, giving a single relationship applicable to a wide range of fractional porosities:

$$
\phi=-1.18+8.607 / \mathrm{V}_{p}-17.89 / \mathrm{V}_{p}{ }^{2}+13.94 / \mathrm{V}_{p}{ }^{3}
$$

\section{Observations}

Plots of sonic traveltime vs. porosity for the five logged holes from Leg 146 are shown in Figures 8A-8D. Also shown on the plots are RMA correlation lines; summary statistics are given in Table 1.
Only one interval, the upper portion of Hole $889 \mathrm{~A}$, exhibited pronounced curvature for the relationship of sonic traveltime to porosity. For that interval, therefore, we used polynomial regression rather than RMA.

Although we have used core porosities as a check on the reliability of $\log$ plots of porosity vs. depth, we cannot do the same for log crossplots of porosity vs. velocity. Whereas core measurements overestimate porosity by a modest amount owing to rebound, most core velocities for uncemented sediments are much lower than log velocities at similar depths (e.g., Jarrard et al., 1993). This pattern, seen in unlithified sediments from nearly all DSDP and ODP legs, reflects the lowering of rigidity associated with both rebound (Hamilton, 1979; Hamilton and Bachman, 1982) and core disturbance. Furthermore, core-based studies of prism porosity cannot evaluate openfracture porosity and its relationship to velocity.

If clay content has the same softening and slowing effect on velocities of high-porosity sediments as for the low-porosity sediments studied by Castagna et al. (1985), Han et al. (1986), and Tosaya and Nur (1982), then we should plot different lithologies separately in Figure 8 . We have used Z-plots of porosity vs. sonic traveltime, with our lithology logs as the $Z$ variable, to examine this possibility. A slight lithology-dependence to the porosity/sonic relationship may be present within Sites 889 and 892 , but it is not observed with enough consistency (e.g., at both Holes 889A and 889B for the same depths, or using both neutron and density porosities) to be considered significantly above the noise level of our data. A significant lithology dependence is detected, however, within the primary undeformed data set-reference Site 888 .

We have already seen that the porosity/formation-factor relationship is lithology-dependent at Site 888 but not detectably so in the 

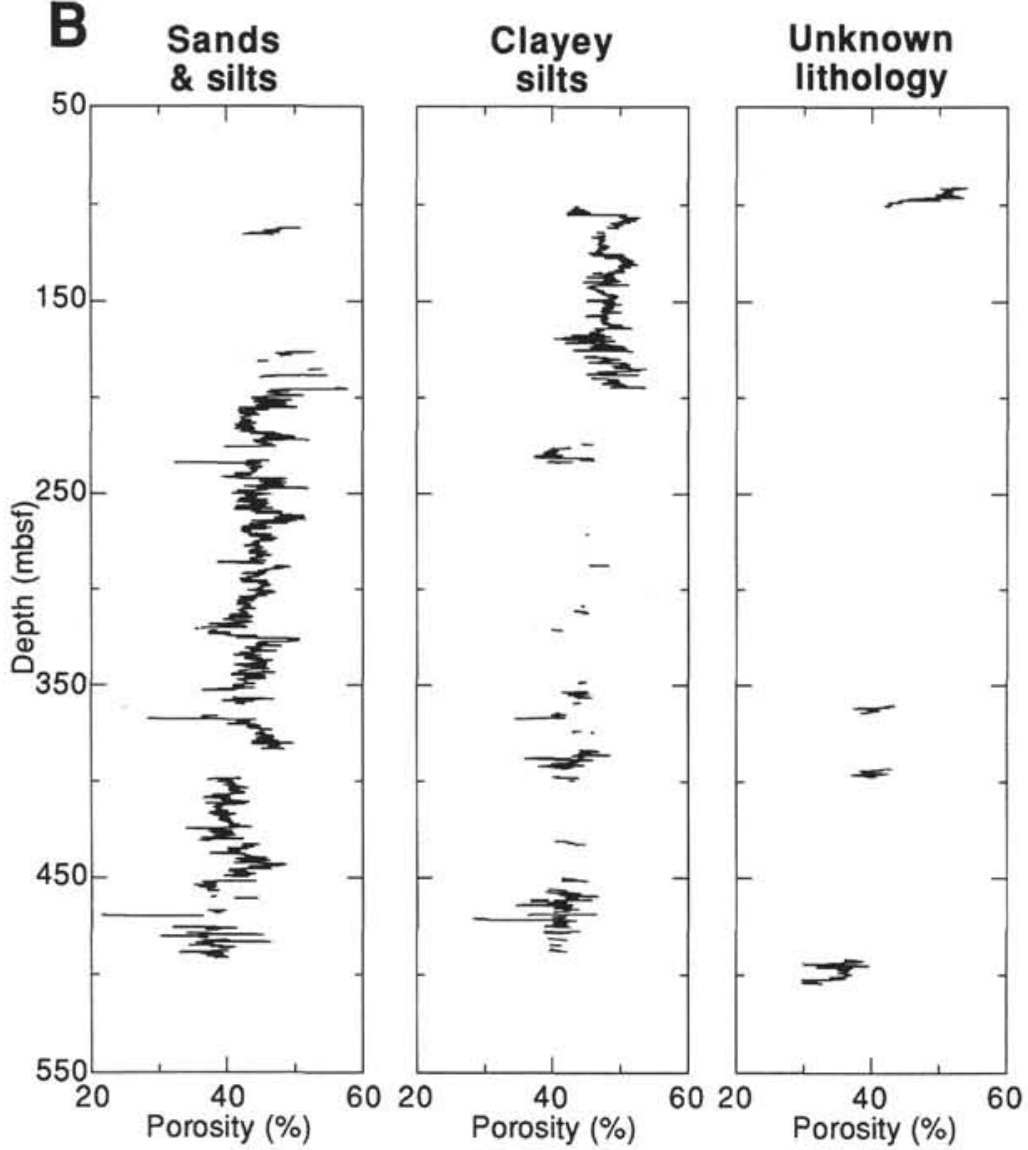

Figure 7 (continued).

prism sediments. As a consequence, only for this site we used lithology in the calculation of porosity from formation factor. Can the apparent lithology dependence of the porosity/sonic relationship be an artifact of this inclusion? The answer to this question is no; the inclusion of lithology dependence in the porosity/formation-factor relationship actually decreases the apparent lithology dependence of porosity vs. traveltime. Figure 9 shows plots of sonic traveltime vs. both formation factor and density porosity, for clayey silts and for combined sands and silts at Site 888 . The extra clay content of clayey silts clearly has a significant effect on these relationships. Based on examination of the sonic/formation-factor plot of Figure 9, one cannot distinguish between two possible effects of clays: they may either increase formation factor (by increasing tortuosity of pore interconnections) or increase sonic traveltime (because clay minerals are much less rigid than quartz and feldspar grains). Using density porosity as a standard demonstrates that both effects are probably present. Figure 5 shows that clayey silts are higher in formation factor than sandier sediments for a given porosity, and Figure 9 shows that they are also higher in sonic traveltime.

These lithologic dependences of porosity/formation-factor and porosity/sonic-traveltime are subtle to absent among sediments studied here from the accretionary prism. Cementation and fracturing, not lithology, are the dominant controls, both on the pore geometry that determines formation factor for a given porosity (Fig. 6), and on the intergranular-contact geometry that determines sonic traveltime for a given porosity (Figs. 9 and 10 ).

Figure 10A summarizes the RMA-determined relationships between porosity and sonic traveltime for undeformed and slightly deformed sediments, and Figure 10B does the same for more heavily deformed and fractured sediments of the accretionary prism. Within each of these two plots, and particularly within Figure 10A, the trend lines define a relatively consistent pattern.
Site 891 data are the exception to the overall consistency within Figures 10A and 10B. The unfractured sediments from the top of Site 891 are anomalously low in porosity, when compared to sediments with similar velocity and lithology from Sites 888 (Fig. 10A), 646 (Jarrard et al., 1989), and 808 (Hyndman, Moore, et al., 1993). Corebased physical-property measurements of these sediments indicate overconsolidation (Shipboard Scientific Party, 1994c), and Figure $10 \mathrm{~A}$ suggests that this overconsolidation effect is greater for porosity than for velocity. Deeper sediments from Site 891 exhibit a progressive change in porosity/traveltime relationship (Fig. 10B), associated with the general downhole increase in velocity in spite of downhole increase in porosity.

Figures $11 \mathrm{~A}$ and $11 \mathrm{~B}$ combine the porosity/velocity data from the different sites and intervals of Figure 10, for fractured and unfractured sediments, respectively. We exclude only the top sediments of Site 891 , because of their anomalous porosity/traveltime pattern. To facilitate comparison with seismic data, we use velocity rather than traveltime in Figure 11. The unfractured sediments of Figure 11 A are well fit $(R=-0.91)$ by a second-order polynomial regression:

$$
V_{p}=3.48-5.42 \times \phi+3.69 \times \phi^{2},
$$

Like all polynomial regressions, however, this one is not expected to be applicable outside the range of the input independent variablefractional porosities of $0.38-0.79$. The fractured sediments of Figure $11 \mathrm{~B}$ exhibit much higher dispersion at low porosities than do the unfractured data, and we consequently use an RMA fit rather than a linear regression. Deleting 17 points $(<1 \%$ of the total points) that have fractional porosities of less than 0.22 and extremely high velocity scatter, the fractured rocks of Figure 11A are moderately well fit $(R=0.81)$ by 

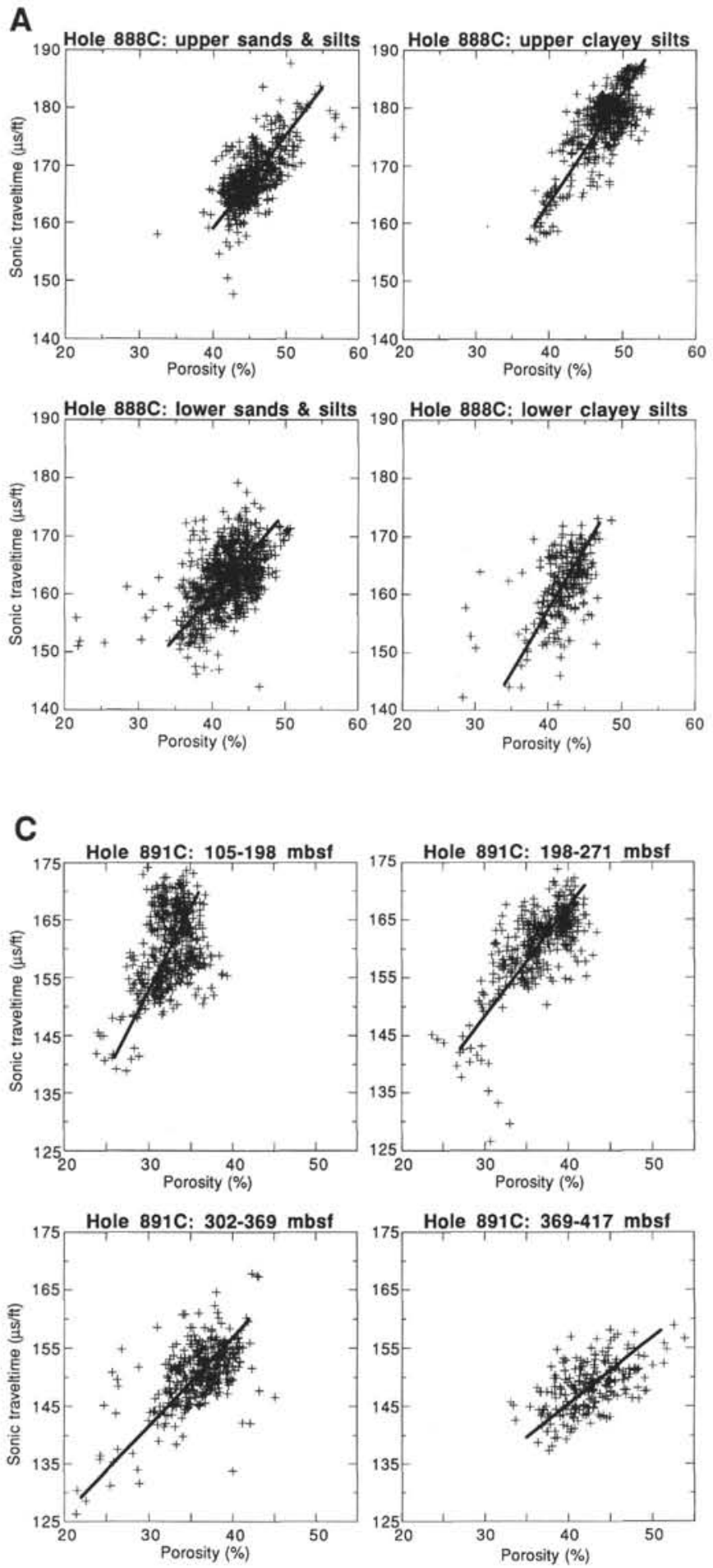

\section{B}
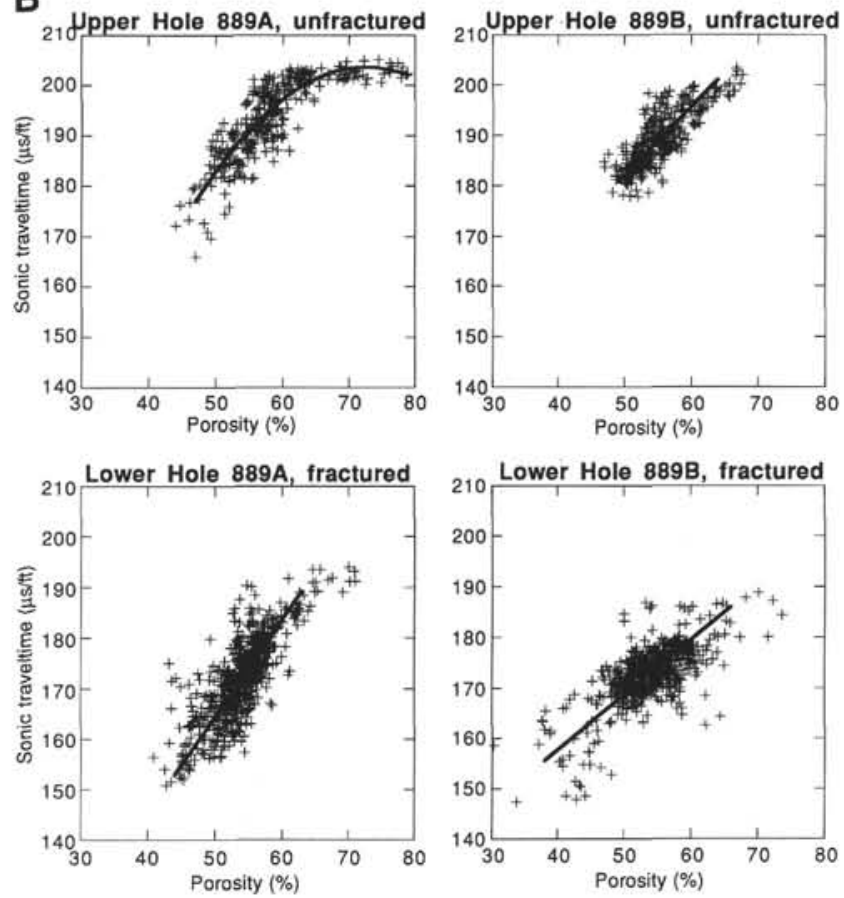

Figure 8. Crossplots of sonic traveltime vs. porosity, for different lithologies (Site 888) or for different structural domains (Sites 889 and 891 ). A. Hole 888C. B. Holes 889A, 889B. C. Hole 891C. D. Hole 892C. Correlation line statistics, based on RMA (polynomial regression for upper Hole 889A), are listed in Table 1.

$$
1 / V_{p}=0.351+0.406 \times \phi .
$$

This equation, which is applicable only for fractional porosities of $0.38-0.68$, clearly fits the upper portion of this porosity range much better than the lower portion (Fig. 11B). This equation seriously underestimates velocities for fractional porosities above 0.68 (Fig. $11 \mathrm{~B})$, but we have so few data above 0.68 that linear and secondorder polynomial regressions give virtually identical results.

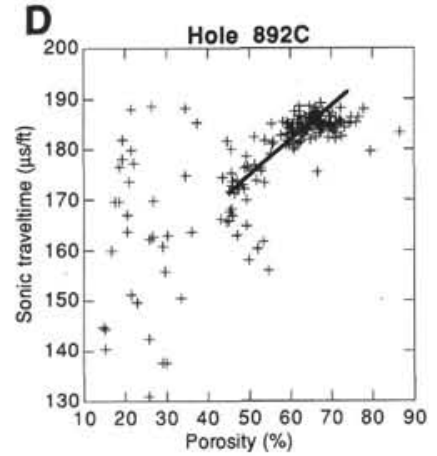

Of the published porosity/velocity relationships, only that of Hyndman, Moore, et al. (1993) fits our data for relatively undeformed sediments reasonably well; it lies consistently about $0.05 \mathrm{~km} /$ s above the trend of Figure 11A. Hyndman, Moore, et al.'s (1993) empirical relationship could not, however, include a lithology-dependent term, although such a term was included by Han et al. (1986) for low porosities, because Jarrard et al. (1989) failed to include lithology dependence in their analysis of high-porosity terrigenous sedi- 
Table 1. Reduced major axis (RMA) correlations between sonic traveltime $(\mu \mathrm{s} / \mathrm{ft})$ and fractional porosity.

\begin{tabular}{|c|c|c|c|c|c|}
\hline Hole & $\begin{array}{l}\text { Depth } \\
\text { (mbsf) }\end{array}$ & RMA equation & $\mathrm{R}$ & Main $\phi$ range & Comments \\
\hline $888 \mathrm{C}$ & $101.3-295.0$ & $\Delta \mathrm{t}=94.0+162 \phi$ & 0.663 & $0.40-0.55$ & Sand and silt \\
\hline $888 \mathrm{C}$ & $295.0-484.0$ & $\Delta \mathrm{t}=102.2+1440$ & 0.506 & $0.34-0.49$ & Sand and silt \\
\hline $888 \mathrm{C}$ & $101.3-295.0$ & $\Delta \mathrm{t}=87.1+191 \phi$ & 0.770 & $0.38-0.53$ & Clayey silt \\
\hline $888 \mathrm{C}$ & $295.0-484.0$ & $\Delta t=71.0+2160$ & 0.532 & $0.34-0.47$ & Clayey silt \\
\hline $889 \mathrm{~A}$ & $71.3-123.0$ & $\Delta t=-10.5+589 \phi-406 \phi^{2}$ & 0.866 & $0.47-0.79$ & \\
\hline $889 \mathrm{~A}$ & $123.1-229.3$ & $\overrightarrow{\Delta t}=68.4+192 \phi$ & 0.791 & $0.44-0.63$ & \\
\hline $889 \mathrm{~B}$ & $71.0-128.5$ & $\Delta \mathrm{t}=113.8+1360$ & 0.801 & $0.49-0.64$ & \\
\hline $889 \mathrm{~B}$ & $128.6-224.7$ & $\Delta \mathrm{t}=114.2+109 \phi$ & 0.716 & $0.38-0.66$ & \\
\hline $891 \mathrm{C}$ & $109.1-198.0$ & $\Delta \mathrm{t}=66.8+286 \phi$ & 0.439 & $0.26-0.36$ & \\
\hline $891 \mathrm{C}$ & $198.1-271.0$ & $\Delta \mathrm{t}=91.6+189 \phi$ & 0.713 & $0.27-0.42$ & \\
\hline $891 \mathrm{C}$ & $302.4-369.0$ & $\Delta t=95.3+1540$ & 0.597 & $0.22-0.42$ & \\
\hline $891 \mathrm{C}$ & $369.2-416.7$ & $\Delta \mathrm{t}=99.1+1160$ & 0.548 & $0.35-0.51$ & \\
\hline $892 \mathrm{C}$ & $38.1-70.7$ & $\Delta t=140.1+69.1 \phi$ & 0.727 & $0.45-0.74$ & \\
\hline
\end{tabular}
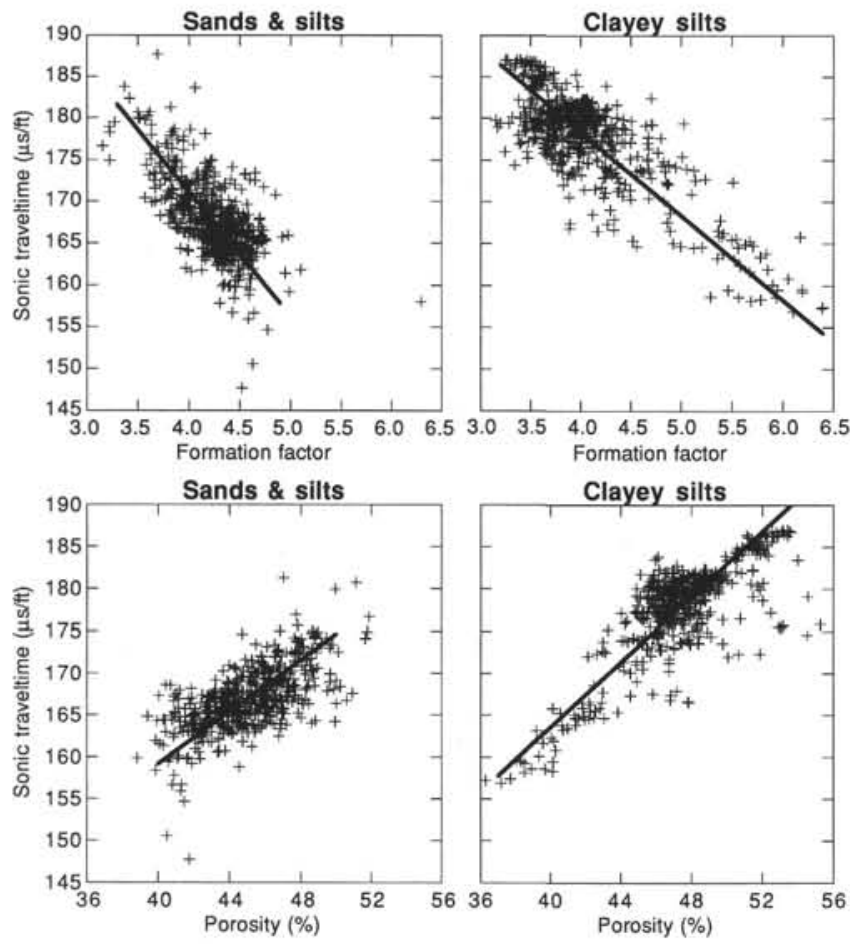

Figure 9. Comparison of sonic traveltimes at Hole $888 \mathrm{C}$ to formation factor and porosity, for two lithologies. Note that the two lithologies have significantly different trends.

ments. The present study does not follow the lead of Hyndman, Moore, et al. (1993) by combining our fit to high-porosity data with Han et al.'s (1986) fit for low porosities, because of the large gap between the two data sets: virtually all of our data have velocities of less than $2.0 \mathrm{~km} / \mathrm{s}$, whereas Han et al.'s (1986) minimum velocity was 3.2 $\mathrm{km} / \mathrm{s}$.

In contrast to the predictive success of the Hyndman, Moore, et al. (1993) relationship, those of Wyllie et al. (1956) and Nobes (1989) overestimate velocities by at least $0.8-2.0$ and $0.2-0.4 \mathrm{~km} / \mathrm{s}$, respectively. The Raymer et al. (1980) and Wood (1941) relationships fit the data well for porosities of $>60 \%$; they even predict the curvature of the relationship, and Raymer et al. (1980) predict the observed velocity minimum at about $70 \%$ porosity. For porosities of less than $60 \%$, however, the two relationships are poor predictors of these data: Wood's relationship greatly underestimates velocity for all porosities below $60 \%$, and Raymer et al.'s (1980) hypothesized plummeting of velocity between porosities of $37 \%$ and $43 \%$ is not observed.

\section{IMPLICATIONS FOR ACCRETIONARY PROCESSES}

To transform MCS-velocity cross-sections to porosity cross-sections and thereby examine prism dewatering processes, one first must have an appropriate velocity/porosity conversion. Yet, comparison of Figures $11 \mathrm{~A}$ and $11 \mathrm{~B}$ shows that undeformed and prism sediments differ significantly in their porosity/velocity relationships: traveltimes are much lower (and velocities are higher) for a given porosity in fractured sediments than in undeformed sediments, at least at high porosities. Is the amount of this downward offset of porosity/sonictraveltime trend dependent on the intensity of deformation? The portions of Holes $889 \mathrm{~A}$ and $889 \mathrm{~B}$ underlying the hemipelagic blanket, as well as all of Hole $892 \mathrm{C}$, are intensely fractured with a wide range of fracture azimuths, so that the recovered core material was often a slivered hash. In these three holes the upward offset of the velocity/ porosity trend is consistently large. Among the fractured rocks of Site 891 , in contrast, the highest velocity/porosity trend is found not in the most deformed rocks, but in the modestly fractured rocks from below the frontal thrust (Fig. 10B). Consequently, the difference between Figures $11 \mathrm{~A}$ and $11 \mathrm{~B}$ cannot be attributed simply to fractures inducing more porosity increase than velocity decrease.

That unconsolidated sediments and heavily deformed prism rocks might have different porosity/velocity relationships is not surprising. The sign of that difference, however, is concept-dependent. One possibility is suggested by analogy between core rebound and accretionary prism processes. We cannot assume that fracturing and exhumation-induced pressure release affect the in situ velocity of prism sediments only through porosity increase. They could instead cause a substantial decrease in velocity by reducing rigidity modulus, without necessarily increasing porosity by much. In this way, fracturing and pressure release could create an entirely new velocity/porosity relationship, offset downward from the one for normally compacted sediments. This postulated offset is, however, opposite to that demonstrated by Figure 11.

Why are velocities higher for a given porosity in fractured sediments than in undeformed sediments? These fractured sediments are broken by the complex pattern of conjugate and other fractures into rhombs, and the material comprising individual rhombs is highly lithified and rigid. Figure 11B suggests that intergranular contacts among the rigid rhombs are sufficiently high to substantially increase velocity, compared to unconsolidated sediments of comparable porosity. Within the highly fractured sediments of accretionary prisms, two scales of porosity - intergranular and fracture-have a combined effect of permitting development of very high porosity, in sediments 

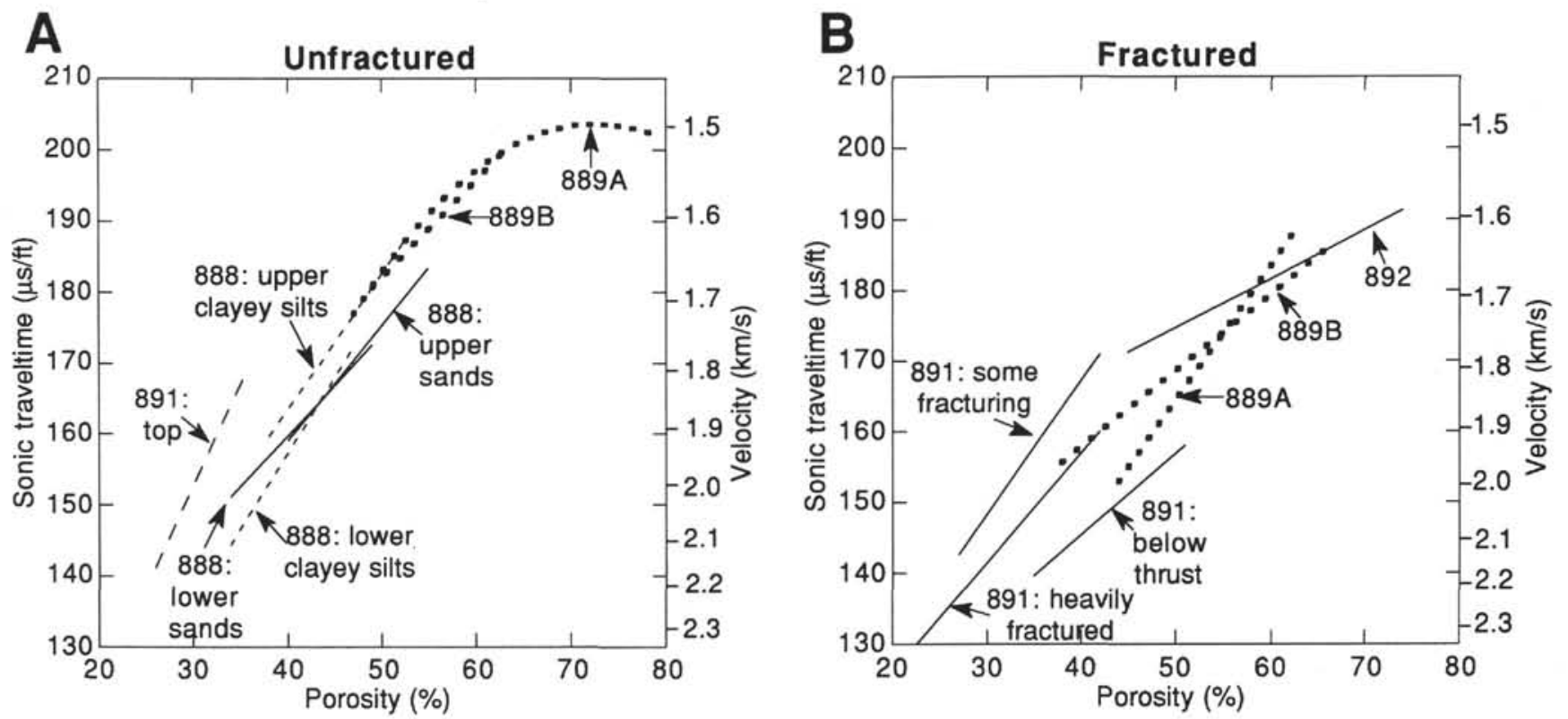

Figure 10. Summary of the relationships between sonic traveltime and porosity shown by the line fits of Figure 8. Both unfractured (A) and fractured (B) rocks show generally similar patterns among different intervals and sites, but note the systematic changes within Site 891 .
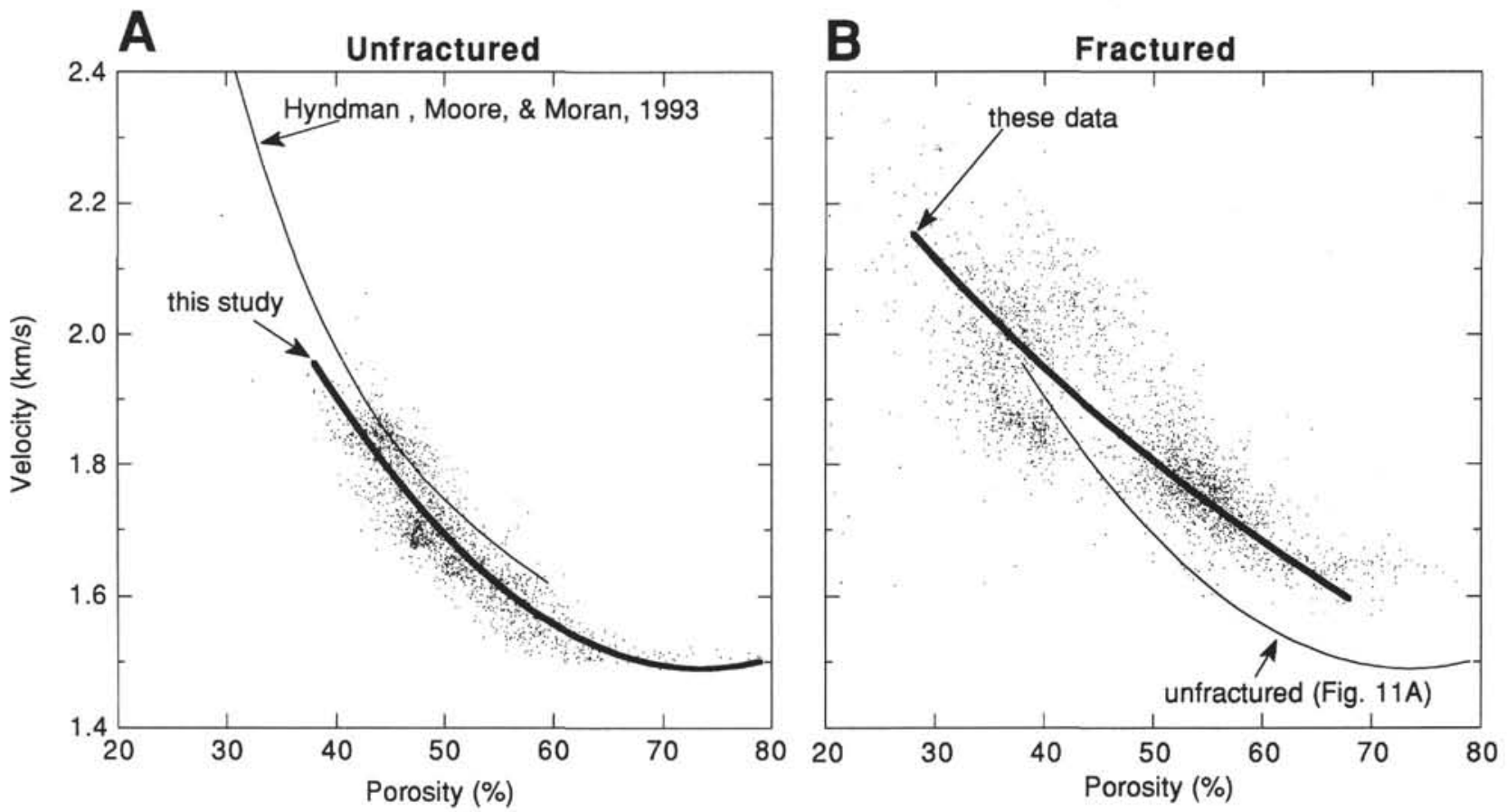

Figure 11. Individual data of Figures 10A (excluding Site 891) and 10B, with bold lines showing the best-fit trends for velocity as a function of porosity. Also shown is a velocity/porosity relationship based on studies of terrigenous sediments by Jarrard et al. (1989) and Han et al. (1986) and consistent with data from Nankai accretionary prism (Hyndman, Moore, et al., 1993). Note that at high porosities, velocities are lower in unfractured rocks (A) than in fractured rocks (B), probably because the latter are much more cemented. Also note the high velocity dispersion at porosities less than $50 \%$ in Figure $11 \mathrm{~B}$, probably attributable to variation in degree of cementation.

that have greater rigidity than unconsolidated sediments of comparable porosity. By the time these latter sediments are consolidated to a porosity of $40 \%$ or less, the discrepancy with prism rocks may become minor (Fig. 11).

For conversion of seismic velocities to porosities within accretionary prisms, the porosity/velocity trend of Figure 11B is much more appropriate than those for undeformed sediments-whether from Figure 11A or from other studies. For such conversions, the data of this study indicate that ignoring minor lithologic variations is probably acceptable; lithologic effects are secondary to structural ones. Previous studies that have converted seismic velocity to porosity based on porosity/velocity relationships for undisturbed sediments (e.g., Bangs et al., 1990; Carson et al., 1991; Hyndman, Wang et al, 1993) probably underestimated the porosity of the upper prism 
and overestimated the porosity change associated with initial accretion. The calculation of fluid expulsion rates within a prism, however, is most sensitive to the slope of the velocity/porosity relationship, which is less subject to error than are absolute porosity estimates. Our data suggest that the porosity difference between accreted and nonaccreted rocks may become minor at velocities of more than $2.2 \mathrm{~km} / \mathrm{s}$, so the overall calculated fluid flux may not be changed substantially; our lower-porosity prism sediments show too much dispersion for precise comparison, however. The paucity of accretionary-prism in situ data for velocities above $2.2 \mathrm{~km} / \mathrm{s}$ lends considerable uncertainty to the use of MCS data for estimation of the fluid budgets of accretionary prisms.

Change in the velocity/depth trend does not start at onset of accretion, or even at the seaward edge of the protothrust region. MCS velocity increases have been observed up to $10 \mathrm{~km}$ seaward of both the Vancouver and Oregon prisms, and they have been attributed to substantial pre-accretion porosity reduction, owing to fluid expulsion (Yuan et al., 1994; Cochran, Moore, et al., 1994). Site 888, 7 km seaward of the toe of Vancouver prism, was intended as a reference site free of accretionary-prism influence. Substantial flow through some portions of the site is documented by geochemical evidence (Shipboard Scientific Party, 1994b), however, and the MCS velocity analysis of Yuan et al. (1994) demonstrates that velocities are elevated with respect to sediments farther from the prism. In contrast to the velocity-based interpretation of compression-induced dewatering, cores from this site exhibited no direct evidence of horizontal compression. Furthermore, logs from this site show a positive correlation between clay content and porosity, an observation that is typical of shallow ( $<1000 \mathrm{mbsf})$ terrigenous sediments from most other regions but that is opposite to the pattern observed in Cascadia prism sediments. We suggest that differential compaction of clay-rich sediments, compared to sandy sediments, is a more sensitive barometer of horizontal compression than is fracture development in high-porosity sediments. Velocity increase prior to accretion may not indicate pervasive dewatering, consequently, and analysis of the mechanical implications of compression to $10 \mathrm{~km}$ seaward of the thrust front (Wang et al., 1994) may not be appropriate. An alternative explanation is pre-accretion cementation, with minor porosity decrease, owing to increased fluid flow.

We attribute the higher velocity/porosity trend for fractured than for unfractured sediments (Fig. 10) primarily to calcite cementation. An alternative explanation is gas hydrates, which enhance velocity without changing porosity. If gas hydrates are more abundant at Sites 889 and 892 than the log analyses of Westbrook, Carson, Musgrave, et al. (1994) and of MacKay et al. (this volume) inferred, then the velocity/porosity trends of these sites are at least partially explained. The similar trend at Site 891 , however, cannot be attributed to gas hydrates.

Many of our Leg 146 velocity and porosity observations, some previously explained and others seemingly anomalous, are consistent with a description of Cascadia porosity and velocity evolution in terms of four partially-overlapping processes: initial depositional undercompaction, flow-induced cementation, compression-induced porosity reduction, and compression-induced fracturing.

Sedimentation rates seaward of the prism off both Vancouver Island and Oregon are up to $1 \mathrm{~km} / \mathrm{m}$.y., enough to induce undercompaction. Accordingly, measurements of shear strength suggest that much of Site 888 plus the portion of Site 891 below the frontal thrust are underconsolidated. Although porosities in most of Site 888 are actually lower than terrigenous reference curves of Brückmann (1989) and Hamilton (1976), the lack of a compaction trend between about 150 and 500 mbsf is suggestive of sedimentation-rate induced undercompaction. The highest porosities logged at Site 891 are in the deepest portion - that beneath the frontal thrust - and only that interval has porosities that are similar to those at Site 888 and similar to expected porosities for those depths.
The deeper portion of Site 891 does not, however, have velocities or formation factors typical for its porosities, and the same may be true for deeper Site 888 . The sediments below the frontal thrust at Site 891 exhibit the highest velocities, in comparison to porosity, of any of the Leg 146 velocity/porosity relationships that we established (Fig. 10). For Site 888 below 295 mbsf, we noted previously that velocity and formation factor increase, in spite of evidence from density and neutron logs of porosity increase. Consequently, we based that porosity/velocity analysis (Fig. 10A) on porosities estimated from formation factors using a porosity/formation-factor relationship from the overlying interval. If the density porosities for the lower interval are reliable, however, then the velocity/porosity relationships for deep sediments at Site 888 are shifted towards higher porosities, in better agreement with lower Site 891 than with other undeformed sediments. For the deep portions of both Sites 888 and 891 , cementation is virtually the only plausible cause of the anomalously high velocities of these high-porosity sediments, and fluid flow is the most likely agent for inducing this cementation. Core analyses from the lower portions of both sites do indicate up to a few percent calcite.

A possible alternative explanation for the high velocities in the lower portions of Sites 888 and 891 is stress-induced velocity increase. We have noted, however, the lack of evidence for differential compaction of clay-rich intervals at Site 888 . For Site 891, minor faulting was observed in cores from beneath the frontal thrust. Much greater horizontal stress is expected above the frontal thrust, howev$\mathrm{er}$, and much more pervasive fracturing was observed there (Shipboard Scientific Party, 1994c), yet velocities for comparable porosities are substantially lower above the thrust than below it (Fig. 10B).

Sediments above the frontal thrust at Site 891 appear to show the emerging dominance of horizontal compression on porosity and velocity, associated with initial accretion. Even at this very early stage of accretion, clay-rich intervals are more compacted than sandier intervals. Porosities for the upper portion of the logged interval here are far lower than in any other intervals logged on Leg 146, and the top sediments have such an anomalous velocity/porosity relationship (Fig. 10A) that we omitted them when establishing our overall relationship for unfractured sediments. Horizontal compression has developed porosities typical of $600-700 \mathrm{mbsf}$ burial, apparently without the extent of cementation that is common at such depths; velocities are, consequently, anomalously low for these porosities. Porosities actually increase substantially downhole, without an accompanying velocity decrease; the velocity/porosity relationship therefore changes systematically with depth (Fig. 10). The most recent motion on the frontal thrust appears to be significantly steeper than the older portion of this thrust (Cochrane, MacKay, et al., 1994), and perhaps bending of the overlying sediments has caused a resulting downhole decrease in horizontal compression and compaction. Alternatively, the downhole increase in fracturing (Shipboard Scientific Party, 1994c) may account for much of the 5-7 porosity-unit increase in porosity. This downhole porosity increase, however, must be accompanied by greater cementation, because velocity increases downhole instead of decreasing.

Horizontal compression and flow-induced cementation undoubtedly continue far landward of the prism toe, and yet the sediments at landward Holes 889A, 889B, and $892 \mathrm{C}$ have porosities extending even higher than Sites 888 and 891 . These sediments are heavily fractured, a consequence of continued compression as cementation changes deformation style from plastic to brittle, and the fracturing causes the high porosities. Fracture porosity has not masked the initial, plastically-induced pattern of higher porosities in sandier intervals than in shaly intervals; fracturing may even be more abundant in sandier intervals than in shaly intervals because of higher rigidity. In spite of the high fracture porosity, rigidity must be higher than in undeformed and unconsolidated sediments of the same porosity, because velocities are higher (Fig. 10). 
These four processes-initial depositional undercompaction, flow-induced cementation, compression-induced porosity reduction, and compression-induced fracturing - each appear to affect both porosity and the velocity/porosity relationship. We think, however, that flow-induced cementation is the key variable, and that its role should be included in future MCS-based interpretations of prism dewatering.

\section{ACKNOWLEDGMENTS}

We thank the Shipboard Scientific Party of Leg 146, and in particular fellow logging scientists C. Moore and K. Rodway and the physical properties scientists, for the team effort that made collection and analysis of these data fruitful. We thank Schlumberger Logging Engineer Steven Kittredge and ODP Operations Superintendent Glen Foss for their calm and professional handling of many logging-related operational emergencies. We thank Roy Hyndman for his insightful and constructive review. This research was supported by the U. S. Science Support Program, USSSP Account \#146-20774b.

\section{REFERENCES}

Anderson, R.N., O'Malley, H., and Newmark, R.L., 1985. Use of geophysical logs for quantitative determination of fracturing, alteration, and lithostratigraphy in the upper oceanic crust, Deep Sea Drilling Project Holes 504B and 556. In Anderson, R.N., Honnorez, J., Becker, K., et al., Init. Repts. DSDP, 83: Washington (U.S. Govt. Printing Office), 443478.

Archie, G.E., 1942. The electrical resistivity $\log$ as an aid in determining some reservoir characteristics. J. Pet. Tech., 5:1-8.

Bangs, N.L.B., Westbrook, G.K., Ladd, J.W., and Buhl, P., 1990. Seismic velocities from the Barbados Ridge Complex: indicators of high pore fluid pressures in an accretionary complex. J. Geophys. Res., 95:87678782.

Bray, C.J., and Karig, D.E., 1985. Porosity of sediments in accretionary prisms, and some implications for dewatering processes. J. Geophys. Res., 90:768-778.

Broglia, C., and Ellis, D., 1990. Effect of alteration, formation absorption, and standoff on the response of the thermal neutron porosity log in gabbros and basalts: examples from Deep Sea Drilling Project-Ocean Drilling Program sites. J. Geophys. Res., 95:9171-9188.

Broglia, C., and Moos, D., 1988. In-situ structure and properties of 110-Ma crust from geophysical logs in DSDP Hole 418A. In Salisbury, M.H., Scott, J.H., et al., Proc. ODP, Sci. Results, 102: College Station, TX (Ocean Drilling Program), 29-47.

Brückmann, W., 1989. Typische Kompakationsmuster mariner Sedimente und ihre Modifikation in einem rezenten Akkretionskeil (Barbados Ridge). Beitr. Geol. Inst. Univ. Tübingen, Rh. A, 5:1-135.

Carslaw, H.S., and Jaeger, J.C., 1947. Conduction of Heat in Solids: Oxford (Clarendon Press).

Carson, B., Holmes, M.L., Umstattd, K., Strasser, J.C., and Johnson, H.P., 1991. Fluid expulsion from the Cascadia accretionary prism: evidence from porosity distribution, direct measurements, and GLORIA imagery Philos. Trans. R. Soc. London A, 335:331-340.

Castagna, J.P., Batzle, M.L., and Eastwood, R.L., 1985. Relationships between compressional-wave and shear-wave velocities in clastic silicate rocks. Geophysics, 50:571-581.

Cochrane, G.R., MacKay, M.E., Moore, G.F., and Moore, J.C., 1994. Consolidation and deformation of sediments at the toe of the central Oregon accretionary prism from multichannel seismic data. In Westbrook, G.K., Carson, B., Musgrave, R.J., et al., Proc. ODP, Init. Repts., 146 (Pt. 1): College Station, TX (Ocean Drilling Program), 421-426.

Cochrane, G.R., Moore, J.C., MacKay, M.E., and Moore, G.F., 1994. Velocity and inferred porosity model of the Oregon accretionary prism from multichannel seismic reflection data: implications on sediment dewatering and overpressure. J. Geophys. Res., 99:7033-7043.

Davis, D., Suppe, J., and Dahlen, F.A., 1983. Mechanics of fold-and-thrust belts and accretionary wedges. J. Geophys. Res., 88:1153-1172.

Davis, E.E., Hyndman, R.D., and Villinger, H., 1990. Rates of fluid expulsion across the northern Cascadia accretionary prism: constraints from new heat flow and multichannel seismic reflection data. J. Geophys. Res. 95:8869-8889.
Dresser Atlas, 1982. Well Logging and Interpretation Techniques, The Course for Home Study (3rd ed.), U.S.A. (Dresser Atlas Industries).

Fulthorpe, C.S., Schlanger, S.O., and Jarrard, R.D., 1989. In situ acoustic properties of pelagic carbonate sediments on the Ontong Java Plateau. $J$. Geophys. Res., 94:4025-4032.

Gassmann, F., 1951. Elastic waves through a packing of spheres. Geophysics, 16:673-685.

Hamilton, E.L., 1976. Variations of density and porosity with depth in deepsea sediments. J. Sediment. Petrol., 46:280-300. 1979. Sound velocity gradients in marine sediments. J. Acoust. Soc. Am., 65:909-922.

Hamilton, E.L., and Bachman, R.T., 1982. Sound velocity and related properties of marine sediments. J. Acoust. Soc. Am., 72:1891-1904.

Han, D., Nur, A., and Morgan, D., 1986. Effects of porosity and clay content on wave velocities in sandstones. Geophysics, 51:2093-2107.

Hardman, R.H., and Shen, L.C., 1986. Theory of induction sonde in dipping beds. Geophysics, 51:800-809.

Hyndman, R.D., Moore, G.F., and Moran, K., 1993. Velocity, porosity, and pore-fluid loss from the Nankai subduction zone accretionary prism. In Hill, I.A., Taira, A., Firth, J.V., et al., Proc. ODP, Sci. Results, 131: College Station, TX (Ocean Drilling Program), 211-220.

Hyndman, R.D., and Spence, G.D., 1992. A seismic study of methane hydrate marine bottom simulating reflectors. J. Geophys. Res., 97:66836698.

Hyndman, R.D., Wang, K., Yuan, T., and Spence, G.D., 1993. Tectonic sediment thickening, fluid expulsion, and the thermal regime of subduction zone accretionary prisms: the Cascadia margin off Vancouver Island. $J$. Geophys. Res., 98:21865-21876.

Jackson, P.D., and Jarrard, R.D., 1993. Integration of SFL and ILD electrical resistivity logs during Leg 133: an automatic modeling approach. In McKenzie, J.A., Davies, P.J., Palmer-Julson, A., et al., Proc. ODP, Sci. Results, 133: College Station, TX (Ocean Drilling Program), 687-694.

Jackson, P.D., Jarrard, R.D., Pigram, C.J., and Pearce, J.M., 1993. Resistivity/porosity/velocity relationships from downhole logs: an aid for evaluating pore morphology. In McKenzie, J.A., Davies, P.J., Palmer-Julson, A., et al., Proc. ODP, Sci. Results, 133: College Station, TX (Ocean Drilling Program), 661-686.

Jackson, P.D., Taylor Smith, D., and Stanford, P.N., 1978. Resistivity-porosity-particle shape relationships for marine sands. Geophysics, 43:12501268.

Jarrard, R.D., Dadey, K.A., and Busch, W.H., 1989. Velocity and density of sediments of Eirik Ridge, Labrador Sea: control by porosity and mineralogy. In Srivastava, S.P., Arthur, M.A., Clement, B., et al., Proc. ODP, Sci. Results, 105: College Station, TX (Ocean Drilling Program), 811835 .

Jarrard, R.D., Jackson, P.D., Kasschau, M., and Ladd, J.W., 1993. Velocity and density of carbonate-rich sediments from northeastern Australian margin: integration of core and log data. In McKenzie, J.A., Davies, P.J., Palmer-Julson, A., et al., Proc. ODP, Sci. Results, 133: College Station, TX (Ocean Drilling Program), 633-647.

Jarrard, R.D., and Symonds, P.A., 1993. Origin of seismic reflectors within carbonate-rich sediments from northeastern Australian margin. In McKenzie, J.A., Davies, P.J., Palmer-Julson, A., et al., Proc. ODP, Sci. Results, 133: College Station, TX (Ocean Drilling Program), 649-659.

Keller, G.V., 1982. Electrical properties of rocks. In Carmichael, R.S. (Ed.), Handbook of Physical Properties of Rocks (Vol. 1): Boca Raton, FL (CRC Press), 217-293.

Le Pichon, X., Henry, P., and Kaiko-Nankai Scientific Crew, 1991. Water budgets in accretionary wedges: a comparison. Philos. Trans. R. Soc. London A, 335:315-330.

Lysne, P., 1989. Investigation of neutron-porosity log uncertainties: Ocean Drilling Program Hole 642E. In Eldholm, O., Thiede, J., Taylor, E., et al., Proc. ODP, Sci. Results, 104: College Station, TX (Ocean Drilling Program), 973-977.

MacKay, M.E., Moore, G.F., Klaeschen, D., and von Huene, R., 1992. Counter-intuitive velocity decrease at the toe of the Oregon accretionary prism. Eos, 73:509.

Mathews, M.A., and von Huene, R., 1985. Site 570 methane hydrate zone. In von Huene, R., Aubouin, J., et al., Init. Repts. DSDP, 84: Washington (U.S. Govt. Printing Office), 773-790.

McManus, D.A., 1991. Suggestions for authors whose manuscripts include quantitative clay mineral analysis by x-ray-diffraction. Mar. Geol., 98:15.

Moore, J.C., and Vrolijk, P., 1992. Fluids in accretionary prisms. Rev. Geophys., 30:113-135. 
Moos, D., 1990. Petrophysical results from logging in DSDP Hole 395A, ODP Leg 109. In Detrick, R., Honnorez, J., Bryan, W.B., Juteau, T., et al., Proc. ODP, Sci. Results, 106/109: College Station, TX (Ocean Drilling Program), 237-253.

Nobes, D.C., 1989. A test of a simple model of the acoustic velocity in marine sediments. J. Acoust. Soc. Am., 86:290-294.

Nobes, D.C., Mienert, J., and Dirksen, G.J., 1991. Lithologic control of physical-property interrelationships. In Ciesielski, P.F., Kristoffersen, Y., et al., Proc. ODP, Sci. Results, 114: College Station, TX (Ocean Drilling Program), 657-669.

Olhoeft, G.R., 1981. Electrical properties of rocks. In Touloukian, Y.S., Judd, W.R., and Roy, R.F. (Eds.), Physical Properties of Rocks and Minerals: New York (McGraw-Hill), 257-330.

Raymer, L.L., Hunt, E.R., and Gardner, J.S., 1980. An improved sonic transit time-to-porosity transform. Trans. SPWLA 21st Annu. Log. Symp., Pap. P.

Schlumberger, 1991. Log Interpretation Charts: U.S.A. (Schlumberger Educ. Serv.).

Serra, O., 1986. Fundamentals of Well-Log Interpretation (Vol. 2): The Interpretation of Logging Data: Amsterdam (Elsevier).

Shipboard Scientific Party, 1973. Site 174. In Kulm, L.D., von Huene, R., et al., Init. Repts. DSDP, 18: Washington (U.S. Govt. Printing Office), 97167.

1987. Site 645. In Srivastava, S.P., Arthur, M., Clement, B., et al., Proc. ODP, Init. Repts., 105: College Station, TX (Ocean Drilling Program), 61-418.

, 1994a. Explanatory notes. In Westbrook, G.K., Carson, B., Musgrave, R.J., et al., Proc. ODP, Init. Repts., 146 (Pt. 1): College Station, TX (Ocean Drilling Program), 15-48.

1994b. Site 888. In Westbrook, G.K., Carson, B., Musgrave, R.J., et al., Proc. ODP, Init. Repts., 146 (Pt. 1): College Station, TX (Ocean Drilling Program), 55-125.

, 1994c. Site 891. In Westbrook, G.K., Carson, B., Musgrave, R.J., et al., Proc. ODP, Init. Repts., 146 (Pt. 1): College Station, TX (Ocean Drilling Program), 241-300.
Toksöz, M.N., Cheng, C.H., and Timur, A., 1976. Velocities of seismic waves in porous rocks. Geophysics, 41:621-645.

Tosaya, C., and Nur, A., 1982. Effect of diagenesis and clays on compressional velocities in rocks. Geophys. Res. Lett., 9:5-8.

Urmos, J., Wilkens, R.H., Bassinot, F., Lyle, M., Marsters, J.C., Mayer, L.A., and Mosher, D.C., 1993. Laboratory and well-log velocity and density measurements from the Ontong Java Plateau: new in-situ corrections to laboratory data for pelagic carbonates. In Berger, W.H., Kroenke, L.W., Mayer, L.A., et al., Proc. ODP, Sci. Results, 130: College Station, TX (Ocean Drilling Program), 607-622.

Wang, C., Hwang, W., and Cochrane, G.R., 1994. Tectonic dewatering and mechanics of protothrust zones: example from the Cascadia accretionary margin. J. Geophys. Res., 99:20043-20050.

Wang, M.C., Nacci, V.A., and Markert, C.D., 1976. Electrical resistivity method for marine sediment consolidation study. Proc. 8th Annu. Offshore Technol. Conf., Houston, TX, Pap. 2623.

Waxman, M.H., and Smits, L.J.M., 1968. Electrical conductivities in oilbearing shaly sands. Trans. Am. Inst. Min., Metall. Pet. Eng., 243.

Westbrook, G.K., Carson, B., Musgrave, R.J., et al., 1994. Proc. ODP, Init. Repts., 146 (Pt. 1): College Station, TX (Ocean Drilling Program).

Winsauer, W.O., Shearing, H.M., Jr., Masson, P.H., and Williams, M., 1952. Resistivity of brine saturated sands in relation to pore geometry. AAPG Bull., 36:253-277.

Wood, A.B., 1941. A Textbook of Sound: London (G.L. Bell).

Wyllie, M.R.J., Gregory, A.R., and Gardner, L.W., 1956. Elastic wave velocities in heterogeneous and porous media. Geophysics, 21:41-70.

Yuan, T., Spence, G.D., and Hyndman, R.D., 1994. Seismic velocities and inferred porosities in the accretionary wedge sediments at the Cascadia Margin. J. Geophys. Res., 99:4413-4427.

Date of initial receipt: 1 September 1994

Date of acceptance: 21 March 1995

Ms 146SR-249 